\title{
Aerosol optical properties in the southeastern United States in summer - Part 1: Hygroscopic growth
}

\author{
Charles A. Brock ${ }^{1}$, Nicholas L. Wagner ${ }^{1,2}$, Bruce E. Anderson ${ }^{3}$, Alexis R. Attwood ${ }^{1,2, a}$, Andreas Beyersdorf ${ }^{3}$, \\ Pedro Campuzano-Jost ${ }^{2,4}$, Annmarie G. Carlton ${ }^{5}$, Douglas A. Day ${ }^{2,4}$, Glenn S. Diskin ${ }^{3}$, Timothy D. Gordon ${ }^{1,2, b}$, \\ Jose L. Jimenez ${ }^{2,4}$, Daniel A. Lack ${ }^{1,2, \mathrm{c}}$, Jin Liao ${ }^{1,2, \mathrm{~d}}$, Milos Z. Markovic ${ }^{1,2, \mathrm{e}}$, Ann M. Middlebrook ${ }^{1}$, Nga L. Ng ${ }^{6,7}$, \\ Anne E. Perring ${ }^{1,2}$, Matthews S. Richardson ${ }^{1,2}$, Joshua P. Schwarz ${ }^{1}$, Rebecca A. Washenfelder ${ }^{1,2}$, Andre Welti ${ }^{1,2, f}$, \\ Lu Xü ${ }^{7}$, Luke D. Ziemba ${ }^{3}$, and Daniel M. Murphy ${ }^{1}$ \\ ${ }^{1}$ NOAA Earth System Research Laboratory, Boulder, Colorado, USA \\ ${ }^{2}$ Cooperative Institute for Research in Environmental Sciences, University of Colorado, Boulder, Colorado, USA \\ ${ }^{3}$ NASA Langley Research Center, Hampton, Virginia, USA \\ ${ }^{4}$ Department of Chemistry and Biochemistry, University of Colorado, Boulder, Colorado, USA \\ ${ }^{5}$ Department of Environmental Sciences, Rutgers University, New Brunswick, New Jersey, USA \\ ${ }^{6}$ School of Earth and Atmospheric Sciences, Georgia Institute of Technology, Atlanta, Georgia, USA \\ ${ }^{7}$ School of Chemical and Biomolecular Engineering, Georgia Institute of Technology, Atlanta, Georgia, USA \\ ${ }^{a}$ now at: Droplet Measurement Technologies, Boulder, Colorado, USA \\ bnow at: Handix Scientific, Boulder, Colorado, USA \\ ${ }^{c}$ now at: TEAC Consulting, Brisbane, Australia \\ ${ }^{d}$ now at: NASA Goddard Space Flight Center, Greenbelt, Maryland, USA \\ ${ }^{\mathrm{e}}$ now at: Air Quality Research Division, Environment Canada, Toronto, Ontario, Canada \\ f now at: Department of Physics, Leibniz Institute for Tropospheric Research, Leipzig, Germany
}

Correspondence to: Charles A. Brock (charles.a.brock@noaa.gov)

Received: 26 August 2015 - Published in Atmos. Chem. Phys. Discuss.: 22 September 2015

Revised: 12 February 2016 - Accepted: 24 March 2016 - Published: 22 April 2016

\begin{abstract}
Aircraft observations of meteorological, trace gas, and aerosol properties were made during MaySeptember 2013 in the southeastern United States (US) under fair-weather, afternoon conditions with well-defined planetary boundary layer structure. Optical extinction at $532 \mathrm{~nm}$ was directly measured at relative humidities (RHs) of $\sim 15$, $\sim 70$, and $\sim 90 \%$ and compared with extinction calculated from measurements of aerosol composition and size distribution using the $\kappa$-Köhler approximation for hygroscopic growth. The calculated enhancement in hydrated aerosol extinction with relative humidity, $f(\mathrm{RH})$, calculated by this method agreed well with the observed $f(\mathrm{RH})$ at $\sim 90 \%$ $\mathrm{RH}$. The dominance of organic aerosol, which comprised $65 \pm 10 \%$ of particulate matter with aerodynamic diameter $<1 \mu \mathrm{m}$ in the planetary boundary layer, resulted in relatively low $f(\mathrm{RH})$ values of $1.43 \pm 0.67$ at $70 \% \mathrm{RH}$ and $2.28 \pm 1.05$ at $90 \% \mathrm{RH}$. The subsaturated $\kappa$-Köhler hygroscopicity pa-
\end{abstract}

rameter $\kappa$ for the organic fraction of the aerosol must have been $<0.10$ to be consistent with $75 \%$ of the observations within uncertainties, with a best estimate of $\kappa=0.05$. This subsaturated $\kappa$ value for the organic aerosol in the southeastern US is broadly consistent with field studies in rural environments. A new, physically based, single-parameter representation was developed that better described $f(\mathrm{RH})$ than did the widely used gamma power-law approximation.

\section{Introduction}

Particles in the atmosphere scatter and absorb solar radiation. Atmospheric aerosol extinction (i.e., scattering + absorption) reduces visibility and usually cools the earth, especially over dark surfaces such as oceans and forests. Uncertainty in the direct radiative forcing due to anthropogenic aerosols is the 
second largest contributor to total uncertainty in climate forcing (IPCC, 2013; Bond et al., 2013).

One of the most important factors affecting ambient aerosol optical extinction - and hence visibility, aerosol optical depth (AOD), and direct radiative effects - is the particulate water mass, which depends on both the hydrophilic properties of the aerosol components and the relative humidity (RH). Hygroscopic water uptake changes particle size and refractive index and can lead to dramatic changes in the extinction as a function of RH due to changes in the amount of aerosol liquid water, even when dry mass is constant. Atmospheric RH is highly variable temporally, horizontally, and especially vertically, so aerosol water modulates the relationship between ambient extinction and dry aerosol mass.

The relationship between atmospheric extinction and humidity has long been recognized (e.g., Wright, 1939). The coupling between particle hygroscopicity and composition and optical extinction has been evaluated experimentally and quantitatively since the work of Pilat and Charlson (1966), Covert and Charlson (1972) and Hänel (1972a, b). Understanding the factors controlling the change in extinction or scattering as a function of RH, known as $f(\mathrm{RH})$, is important for evaluating remote sensing measurements (e.g., Brock et al., 2016; Crumeyrolle et al., 2014; Esteve et al., 2012; Ferrare et al., 1998; Hegg et al., 1993; Kotchenruther et al., 1999; van Donkelaar et al., 2015; Voss et al., 2001; Zieger et al., 2011, 2012; Ziemba et al., 2012), aerosol direct radiative forcing calculations (e.g., Attwood et al., 2014; IPCC, 2013; Kahn, 2011; Koloutsou-Vakakis et al., 1998; Nemesure et al., 1995), and atmospheric visibility estimates (e.g., Charlson et al., 1967; Malm et al., 2000). In general, particles composed primarily of organic material and dust are less hygroscopic (Duplissy et al., 2011; Petters and Kreidenweis, 2007; Zieger et al., 2015), while those that are predominantly inorganic take up water more readily (e.g., Petters and Kreidenweis, 2007; Quinn et al., 2005). Particles may exhibit sharp phase transitions as they deliquesce, as well as hysteresis as they effloresce, especially for inorganic compositions (e.g., Santarpia et al., 2005; Tang, 1996; Zieger et al., 2014). Particles dominated by organic compounds are more likely to present more gradual hygroscopic growth with increasing RH without evident phase transition behavior (e.g., Carrico et al., 2005; Zieger et al., 2015).

Because of the chemical complexity of particles and the difficulty in measuring precise molecular composition and relating that to water uptake with increasing $\mathrm{RH}$, it is common to use simplified parameterizations to describe the change in extinction (or scattering) with atmospheric $\mathrm{RH}$ relative to a dry or low-RH state. The most frequently used of these parameterizations is a power-law function known as the "gamma" parameterization, which was first used by Kasten et al. (1969). This empirically derived, single-parameter equation is often written as

$$
\frac{\sigma(\mathrm{RH})}{\sigma\left(\mathrm{RH}_{0}\right)} \equiv f(\mathrm{RH})=\left[\frac{\left(100-\mathrm{RH}_{0}\right)}{(100-\mathrm{RH})}\right]^{\gamma},
$$

where $\sigma(\mathrm{RH})$ is the bulk aerosol extinction at the ambient $\mathrm{RH}$ condition, $\sigma\left(\mathrm{RH}_{0}\right)$ the extinction at the dry (low $\mathrm{RH}$ ) condition $\mathrm{RH}_{0}$, and $\gamma$ is a parameter fitted to the observed data. The $\gamma$ parameterization has been widely used to describe aerosol hygroscopicity (e.g., Attwood et al., 2014; Doherty et al, 2005; Kasten, 1969; Massoli et al., 2009; Quinn et al., 2005). Doherty et al. (2005) and Quinn et al. (2005) showed that in many environments the value of $\gamma$ varies systematically with composition, and especially with the ratio of submicron organic aerosol (OA) mass to the mass of submicron sulfate plus OA. This relationship ignores other aerosol components (e.g. nitrate, ammonia and BC) that are important in controlling hygroscopicity (e.g., Zieger et al., 2015), as well as aerosol size, and thus provides only an approximate prediction of $f(\mathrm{RH})$ when given information on bulk submicron particle composition.

In this paper we examine the change in aerosol extinction at $532 \mathrm{~nm}$ wavelength as a function of RH based on measurements from two airborne field projects in the southeastern US in the summer. This analysis focuses on midday and afternoon data collected when the planetary boundary layer was fully developed because, (1) prior to daytime atmospheric mixing, aerosols may be chemically diverse and externally mixed, leading to complex hygroscopic growth patterns that are hard to characterize (Santarpia et al., 2005); (2) we wish to develop an understanding of aerosol hygroscopicity that is regionally representative, and the well-developed, cloudtopped boundary layer structure examined here is typical of the southeastern US in summertime (Warren et al., 1986); and (3) most of the airborne data were taken in the late morning and afternoon in fair weather. We describe the observed variability in aerosol composition, size distribution, and hygroscopicity characteristics in this environment and evaluate the suitability of $\kappa$-Köhler and Mie theories to represent $f(\mathrm{RH})$. We develop and use a new single-parameter equation that better describes $f(\mathrm{RH})$ in this environment than does the $\gamma$ parameterization (Eq. 1).

This paper is the second of three that analyze in detail the same airborne measurements of aerosol optical properties in the southeastern US. In the first paper (Wagner et al., 2015) we described in detail the flights, the instruments and the observations associated with vertical profiles conducted in this region. In the final paper (Brock et al., 2016), the understanding of aerosol hygroscopicity developed here and the vertical profiles analyzed in Wagner et al. (2015) are used to evaluate the sensitivity of AOD to a range of aerosol and meteorological parameters. 


\section{Methods}

\subsection{Aircraft instrumentation}

We analyze airborne, in situ data measured during the MayJuly 2013 Southeastern Nexus of Air Quality and Climate (SENEX) mission and the portions of the AugustSeptember 2013 Study of Emissions and Atmospheric Composition, Clouds, and Climate Coupling by Regional Surveys $\left(\mathrm{SEAC}^{4} \mathrm{RS}\right)$ projects that were carried out in the southeastern US. The SENEX project used the NOAA WP-3D aircraft (typical airspeed $\sim 100 \mathrm{~m} \mathrm{~s}^{-1}$ ), while the SEAC ${ }^{4} \mathrm{RS}$ project used the NASA DC-8 aircraft $\left(\sim 160 \mathrm{~m} \mathrm{~s}^{-1}\right)$. Details of the instruments, measurements, and methodology for generating regionally representative vertical profiles of aerosol, gas-phase, and meteorological parameters are given by Wagner et al. (2015). Briefly, measurements of the composition of sub-1 $\mu \mathrm{m}$ vacuum aerodynamic diameter (approximately $<0.7 \mu \mathrm{m}$ physical diameter) non-refractory particles were made by aerosol mass spectrometers (AMS; Aerodyne, Billerica, Massachusetts, US; Canagaratna et al., 2007; DeCarlo et al., 2006) each with extensive customization for aircraft use (Bahreini et al., 2008; Dunlea et al., 2009; Middlebrook et al., 2012). The AMS used during SENEX employed a compact time-of-flight mass spectrometer (CToF), while that used during SEAC ${ }^{4} R S$ employed a highresolution time-of-flight mass spectrometer with greater resolving power (HR-ToF; DeCarlo et al., 2006). The mass of black carbon (BC) particles was measured on both projects with the same humidified tandem single-particle soot photometer (SP2; Droplet Measurement Technologies, Boulder, CO, US; Schwarz et al., 2015). Dry particle size distributions from $\sim 0.07$ to $1.0 \mu \mathrm{m}$ were measured with two separate ultra-high-sensitivity aerosol size spectrometers (UHSAS; Particle Metrics, Inc., Boulder, Colorado, US; Brock et al., 2011; Cai et al., 2008), one on each project. Aerosol extinction at $532 \mathrm{~nm}$ wavelength and three relative humidities ( $\sim 15, \sim 70$, and $\sim 90 \%)$ was measured simultaneously with a custom-built multichannel cavity ringdown spectrometer (CRDS; Langridge et al., 2011) on both projects.

Air entering the CRDS passed through a $40 \mathrm{~cm}$ long carbon monolith denuder $(210 \mathrm{cpi} / 30 \mathrm{~mm}$ OD, MAST Carbon, Basingstoke, United Kingdom) to remove semivolatile inorganic and organic gases. The flow was then was dried to a low RH $(\sim 15 \%$, range $8-24 \%)$, below the efflorescence point of atmospherically relevant salts, using multitube Nafion dryers (PD-200T-12MSS, Permapure Inc., Toms River, New Jersey, US) with a sample residence time of $0.25 \mathrm{~s}$. For measurement by the two elevated RH channels, the sample was humidified to $>90 \%$ RH by cooling the sample flow inside Nafion humidifiers (MH-110-12-S-4, Permapure Inc., Toms River, New Jersey, US), causing deliquescence. The sample flow was then reheated to the temperatures of the measurement cells in the instrument, which were controlled using RH sensors (model HMP110, Vaisala Inc.,
Helsinki, Finland) to achieve the desired measurement RH. Typically, one elevated-RH channel measured at $\sim 70 \% \mathrm{RH}$ (actual range $70-73 \%$ ) and the other measured at $\sim 90 \%$ RH (actual range 86-94\%). Data were excluded from analysis when the RH of high-RH channel was $<85 \%$.

Histograms of measured RH values for each CRDS channel are given in the Supplement. The cooling in the humidifiers was $10-15$ and $1-3 \mathrm{~K}$ below the cell temperatures of the medium- and high-RH channels, respectively. Total time of exposure to elevated humidities was $\sim 4 \mathrm{~s}$, of which $0.4 \mathrm{~s}$ was in the cooled section and $3.6 \mathrm{~s}$ was in the warmed section. Calculated and measured $f(\mathrm{RH})$ for $300 \mathrm{~nm}$ ammonium sulfate particles are in agreement within uncertainties (Langridge et al., 2011), indicating that the humidified residence time is sufficient to allow hygroscopic particles to grow to equilibrium. However, the instrument has not been tested with less hygroscopic organic particles that might exhibit kinetic limitations to water uptake. This remains an uncharacterized uncertainty.

The changes in sample temperature in the inlet, sample line, humidifiers, and CRDS cells may lead to loss of semivolatile species. Submicron ammonium nitrate was $<0.04 \mu \mathrm{g} \mathrm{m}^{-3}$ in the daytime during contemporaneous measurements at a ground site in Centreville, Alabama, in June 2013 (Attwood et al., 2014; Guo et al., 2015). The upstream denuder excludes condensation of semivolatile compounds. Because of the initial high level of humidification prior to reheating, the CRDS measurements at elevated RH were made on the metastable (humidified) branch of any deliquescence/efflorescence hysteresis curve. This better represents the likely state of the aged atmospheric aerosol in the cloud-topped planetary boundary layer than would measurements made on the deliquescence branch of the curve. We did not attempt to measure aerosol extinction at ambient humidity because it is difficult to regulate instrument humidity rapidly enough to respond to ambient $\mathrm{RH}$ changes in flight.

A low-turbulence inlet and sampling system (Brock et al., 2011) was used during SENEX. During this project the AMS, CRDS, SP2, and UHSAS sampled downstream of an impactor with $50 \%$ efficiency at $1.0 \mu \mathrm{m}$ aerodynamic diameter $\left(\mathrm{PM}_{1}\right)$. Accounting for particle and air density, typical $50 \%$ impactor efficiency was $\sim 0.7 \mu \mathrm{m}$ physical diameter at the inlet RH, which was measured at $<50 \%$ due to dynamic heating during sampling. Particle loses in the CRDS system were characterized experimentally by Langridge et al. (2011) using particles size-selected with a custom-built differential mobility analyzer (DMA) of the design now available commercially (Brechtel Manufacturing, Inc., Hayward, CA, US). Losses within the instrument were $<1.25 \%$ for submicron particles at $\mathrm{RH}$ values up to $92 \%$. Transmission of $0.1-0.7 \mu \mathrm{m}$ particles in the turbulent transmission line (inner diameter $0.95 \mathrm{~cm}$, length $3 \mathrm{~m}$, flow rate $20 \mathrm{~L} \mathrm{~min}^{-1}$ ) between the impactor and the AMS, CRDS, SP2, and UHSAS was calculated for inertial, gravitational, and diffusive losses using the aerocalc.xls spreadsheet (Baron, 2001) and 
was $>0.992$ for the range of flight conditions encountered. Based on the known particle transmission characteristics of the AMS focusing lens inlet and the measured size distribution, the AMS was estimated to sample $>97 \%$ of $\mathrm{PM}_{1}$ particle volume (Wagner et al., 2015). During SEAC ${ }^{4}$ SS, the aerosol instruments sampled ambient air using a shrouded conical diffusing inlet that transmitted particles smaller than $2.8 \mu \mathrm{m}$ aerodynamic diameter with efficiency $>95 \%$ (McNaughton et al., 2007). The CRDS and UHSAS sampled downstream of the same $1.0 \mu \mathrm{m}$ impactor used in SENEX. Calculated particle transmission through the tubing between the inlet and the CRDS and UHSAS instruments was $>0.99$. The AMS, CRDS, SP2, and UHSAS all comparably and quantitatively sampled $\mathrm{PM}_{1}$ aerosol during both SENEX and SEAC ${ }^{4} \mathrm{RS}$.

The accuracy of the $f(\mathrm{RH})$ measurement made by the CRDS instrument was reported in Langridge et al. (2011) using ammonium sulfate particles size-selected with a DMA as an atmospherically relevant model hygroscopic aerosol and polystyrene latex (PSL) as a model hydrophobic aerosol. The accuracy of $f(\mathrm{RH})$ determined by this approach was within $\pm 2 \%$ (at $\mathrm{RH}=76 \%$ ) and $\pm 14 \%$ (at $\mathrm{RH}=95 \%$ ) of values calculated by $\kappa$-Köhler theory, well within experimental uncertainty. The optical power in the sample cells of the CRDS is much less than the $40-100 \mathrm{~mW}$ lasers that illuminate the optical cavities, and the aerosol is not measurably heated. The humidity is controlled by direct measurement of $\mathrm{RH}$ within each ringdown cell. Because the CRDS provides a fundamental measurement of extinction, repeated extinction calibrations are not necessary. The gas-phase extinction measurement was periodically checked with an ozone source measured by an independent ozone sensor (Thermo Environmental Instruments, model 49i ozone analyzer) and showed no systematic biases in the CRDS extinction during SENEX or SEAC ${ }^{4} \mathrm{RS}$. The probes measuring the RH of the sample cells (Vaisala HMP110) were calibrated before and after the SENEX and SEAC ${ }^{4} \mathrm{RS}$ missions using the equilibrium water vapor pressure over salt solutions (Vaisala HMK15) providing nominal $\mathrm{RH}$ values of $33 \%\left(\mathrm{MgCl}_{2}\right), 75 \%(\mathrm{NaCl})$, and $97 \%\left(\mathrm{~K}_{2} \mathrm{SO}_{4}\right)$. The $\mathrm{RH}$ values reported by probes were within the manufacturer's stated uncertainty of $\pm 2 \%$ for $\mathrm{RH}<90 \%$ and $\pm 3 \%$ for $\mathrm{RH} \geq 90 \%$ for these salt solutions. The total accuracy in the $1 \mathrm{~s}$ humidified extinction measurement is estimated to be $\pm 5, \pm 10$, and $\pm 15 \%$ at $\sim 15, \sim 70$, and $\sim 90 \% \mathrm{RH}$, respectively. Thus the uncertainty in $f(\mathrm{RH})$ is estimated to be \pm 11 and $\pm 16 \%$ for the medium- and high$\mathrm{RH}$ channels, respectively. This uncertainty estimate does not account for possible residual water present in particles in the $\sim 15 \% \mathrm{RH}$ channel, which could bias the $f(\mathrm{RH})$ values low.

\subsection{Corrections to UHSAS size distributions for refractive index}

The size distribution reported by the UHSAS is a function of the amount of light scattered onto the instrument's photode- tectors, and the quantity of scattered light is itself a function of the composition-dependent aerosol refractive index. Hence, it is necessary to correct the measured UHSAS size distributions for changing aerosol composition during flight. This correction was accomplished by first calibrating the instrument to an aerosol of known refractive index to relate scattering amplitude to discrete pulse height channels. Next, the Mie scattering over the optical geometry of the instrument was calculated to determine how each channel was related to particle diameter for an atmospherically relevant range of real refractive index. Finally, a look-up table of this relationship was used to determine the actual diameter represented by each channel as refractive index, calculated from the AMS measurements as described in Sect. 2.3, varied. The UHSAS exhibits a monotonic response function for submicron particles (Cai et al., 2008).

The UHSAS operated during SENEX was calibrated using atomized, dried ammonium sulfate particles sized with the DMA previously described. The sizing accuracy of the DMA was better than $2 \%$ as determined using NIST-traceable PSL microspheres in eight sizes from 0.1 to $1.2 \mu \mathrm{m}$ (Thermo Fisher Scientific, Inc., Waltham, MA, US). The UHSAS was calibrated on 5 days with $>36$ separate ammonium sulfate particle sizes during the SENEX mission, in addition to preflight daily calibration checks using four PSL microsphere sizes. The UHSAS that was operated by the NASA Langley group during SEAC ${ }^{4} \mathrm{RS}$ was calibrated using PSL microspheres and the calibration was checked twice during each flight by generating an aerosol containing four microsphere sizes and introducing it into the inlet sample flow as the aircraft was flying.

The response of the UHSAS was simulated using numerical Mie calculations (Bohren and Huffman, 1983) of the light scattered over the solid angle that is imaged onto the instrument's photodetectors. Assumptions include spherical, homogeneous particles with composition that is invariant with particle diameter. The geometry of the detection optics was determined from a review of technical drawings with the manufacturer. Light is scattered perpendicularly to the beam from a neodymium-doped yttrium lithium fluoride laser $(1053 \mathrm{~nm})$ and is imaged onto solid-state photodetectors on each side of the scattering cell using pairs of Mangin mirrors in clamshell configurations. The signal from each detector is amplified through two gain stages, for a total of four independent gain stages. Each detector samples the light scattered by particles over a circularly symmetric angle from 33 to $147^{\circ}$. The center region of the angle, between 75.2 and $104.8^{\circ}$, is not sampled because of the hole cut in the outer of the Mangin mirrors (the detector area is a negligible fraction of this hole area). Thus the imaged solid angle is a conical annulus. This geometry is consistent with that reported by Petzold et al. (2013), but contrasts with that reported for the UHSAS by Cai et al. (2008), who appear to have incorrectly used a $22-158^{\circ}$ scattering angle to simulate UHSAS instrument response. 
Using the calibrations, the relationship between the 99 size channels and the amount of light scattered onto the detectors was determined. Knowing that each channel represents a certain amount of scattered light, the Mie model was used to calculate the particle diameter corresponding to each channel for a range of particle real refractive indices from 1.40 to 1.60 , in increments of 0.01 , producing a look-up table relating channel number to particle diameter as a function of real refractive index. Using the AMS data and the composition model described in Sect. 2.3, the real refractive index was determined by volume-weighted averaging for each AMS data point using the values in Table 1 . The mean and standard deviation of the real part of the calculated refractive index was $1.547 \pm 0.004$ for the data analyzed here. Using the real refractive index for each point, the look-up table was then applied to determine the physical diameter for each UHSAS channel for each measurement interval. Residual water content in the dry $(\sim 15 \% \mathrm{RH})$ aerosol was not considered. The variation in instrument response due to the imaginary component of the refractive index, $k$, also was not considered. Because BC concentrations measured by the SP2 were very low (averaging $<0.05 \mu \mathrm{g} \mathrm{m}^{-3}$ for the data analyzed here), $k$ was calculated to be $0.006 \pm 0.004$, and thus was ignored in the generation of the UHSAS look-up table. However, the BC component was included in the calculation of $\kappa_{\text {chem }}$, refractive index, and extinction as described in Sect. 2.3 below.

\subsection{Method to calculate ambient extinction}

To determine ambient extinction, measurements of extinction made at three discrete RH values of $\sim 15, \sim 70$, and $\sim 90 \%$ may be interpolated or extrapolated to ambient conditions at arbitrary RH based on a parametric model such as the $\gamma$ function. However, because the measurements analyzed here include submicron aerosol size distributions and composition, a more explicit method to determine ambient extinction can also be used (Fig. 1a). Petters and Kreidenweis (2007) proposed the $\kappa$-Köhler parameterization that describes the water activity of an aqueous solution without considering explicitly the effect of individual ionic components. The $\kappa$-Köhler approach has been used widely to predict subsaturated particle growth as well as the activation of cloud condensation nuclei $(\mathrm{CCN})$. Ignoring curvature effects for particles diameters $>100 \mathrm{~nm}$, the hygroscopic growth of a water-soluble aerosol can be approximated as

$\mathrm{gf}_{\text {diam }} \cong\left(1+\kappa_{\text {chem }} \frac{\mathrm{RH}}{100-\mathrm{RH}}\right)^{1 / 3}$,

where $\mathrm{gf}_{\text {diam }}$ is the diameter growth factor, the ratio of the particle's wet diameter to its dry diameter. An equation of this form was first used by Rissler et al. (2006) to describe observed hygroscopic growth factors. The value of $\kappa_{\text {chem }}$ for a mixed particle composition may be calculated from the volume-weighted average of the $\kappa_{\text {chem }}$ of each species $i, \kappa_{i}$,

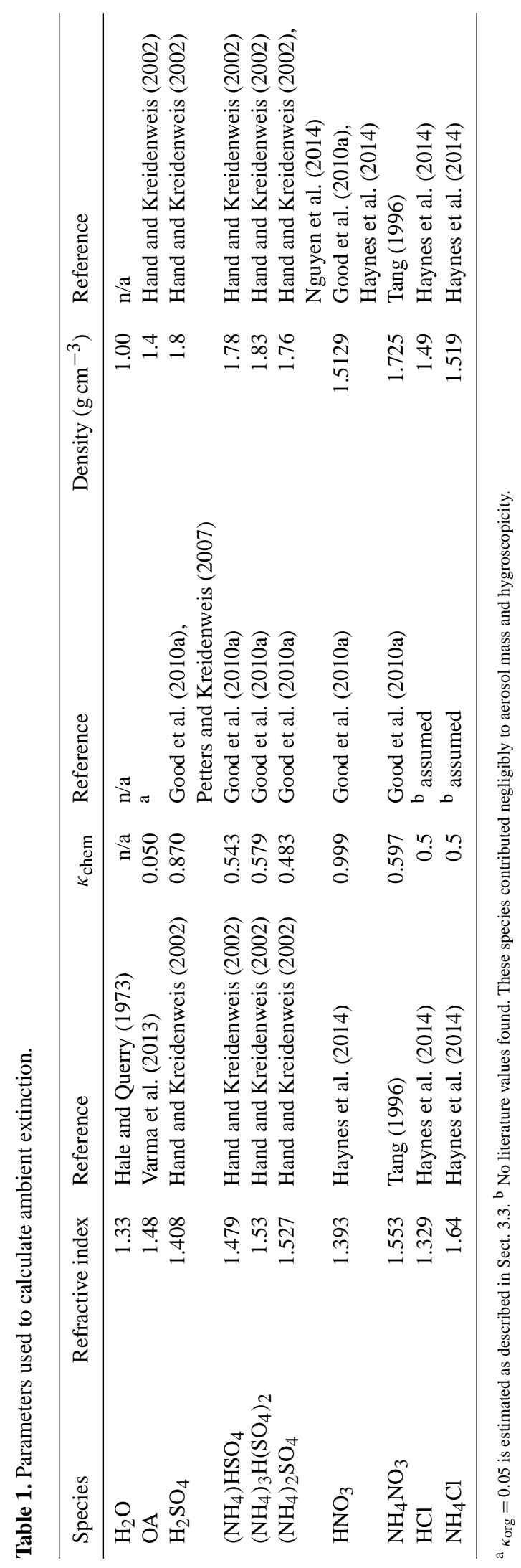

Atmos. Chem. Phys., 16, 4987-5007, 2016 
which contributes to the aerosol composition:

$\kappa_{\text {chem }}=\frac{\sum_{i}\left(\kappa_{i} X_{i} / \rho_{i}\right)}{\sum_{i}\left(X_{i} / \rho_{i}\right)}$,

where $X_{i}$ is the mass concentration and $\rho_{i}$ the dry density of species $i$. The $\kappa_{i}$ are determined from thermodynamic model calculations or by experimentally determining the growth factors for individual compounds. This volume-weighted approach follows the Zdanovskii-Stokes-Robinson (Stokes and Robinson, 1966) mixing rule, which states that each component of the mixture acts independently and that the optical properties are linearly additive. The accuracy of the particle diameter growth factor calculated using $\kappa_{\text {chem }}$ determined from Eq. (3) varies depending on the specifics of the aerosol composition and mixing state and on the accuracy of the $\kappa_{i}$, but is generally observed to be better than $30 \%$ (Petters and Kreidenweis, 2007).

Using the methodology shown schematically in Fig. 1a, the measurements of aerosol composition and size distribution were used to calculate the extinction expected at the dry, medium, and high RH values measured in the CRDS. This calculation serves two purposes: it evaluates the closure of the optical, chemical, and size distribution measurements, and it helps determine how well the $\gamma$ parameterization, Eq. (1), describes $f(\mathrm{RH})$ in the southeastern US. The AMS measured the mass concentrations of sulfate, nitrate, chloride, ammonium, and OA. From these measurements, an electrolyte composition model (Zaveri, 2005) was used to calculate the concentrations of ammonium sulfate, ammonium bisulfate, letovicite, sulfuric acid, ammonium nitrate, ammonium chloride, nitric acid, and hydrochloric acid. Contributions from ions associated with electrolytes of magnesium and sodium are likely to be insignificant contributors to the submicron aerosol mass in the continental boundary layer (Washenfelder et al., 2015). Organosulfates were estimated to contribute $<4 \%$ to the submicron aerosol mass and therefore are not considered (Liao et al., 2015). The contribution of particulate organic nitrates (pON) to measured nitrate has been estimated using the method described in Fry et al. (2009) for the SEAC ${ }^{4} \mathrm{RS}$ flights on which the HR-ToFAMS was operated (Day et al., 2016). The pON, likely in the form of oxidized monoterpene nitrates (Boyd et al., 2015; Draper et al., 2015; Xu et al., 2015a, b), is estimated to be between 15 and $40 \%$ of the total measured nitrate above the surface in the well-mixed and transition layers, and more than $63 \%$ across the southeastern US at the surface (Xu et al., 2015a). However, nitrate represented $<5 \%$ of fine aerosol mass in the data analyzed here. Lacking specific information on pON density or hygroscopicity, and given its relatively small contribution to aerosol mass in summer $(<12 \%$ of OA and $<8 \%$ of submicron mass; Xu et al., 2015b), all measured nitrate is treated as ammonium nitrate. Finally, potential phase separation phenomena that have been found in laboratory studies of OA/inorganic mixtures (e.g., Hodas et al., 2015), insoluble inclusions that might influence hygroscopicity (Pringle et al., 2010), and the diameter dependence of $\kappa_{\text {chem }}$ discussed by Good et al. (2010a) are ignored.

The bulk aerosol $\kappa_{\text {chem }}$ was determined from the volumeweighted $\kappa_{i}$ values (Table 1) using Eq. (3). Aerosol extinction at the measured low, medium and high humidities was then calculated as follows (Fig. 1a). First, as detailed in Sect. 2.2., the optically equivalent dry diameters measured by the UHSAS were converted into physical dry diameters, accounting for the effects of varying composition on the real refractive index, which varied only slightly (interdecile range 1.54-1.56). Next, the particle diameter at the ambient RH, $D_{\mathrm{RH}}$, was calculated using $\kappa$-Köhler theory (including the Kelvin effect) by numerically solving

$$
\frac{\mathrm{RH}}{100}=\frac{D_{\mathrm{RH}}^{3}-D_{\mathrm{d}}^{3}}{D_{\mathrm{RH}}^{3}-D_{\mathrm{d}}^{3}\left(1-\kappa_{\mathrm{chem}}\right)} \exp \left(\frac{4 \sigma_{\mathrm{s}} M_{\mathrm{w}}}{R T \rho_{\mathrm{W}} D_{\mathrm{RH}}}\right),
$$

where $D_{\mathrm{d}}$ is the dry diameter, $\sigma_{\mathrm{s}}$ the surface tension of water at the particle/air interface, and $M_{\mathrm{W}}$ and $\rho_{\mathrm{w}}$ the molecular weight and density of water, respectively (Petters and Kreidenweis, 2007). Finally, Mie theory (Bohren and Huffman, 1983) was used to calculate the expected extinction coefficient, $\sigma_{\text {ext }}$, at the ambient $\mathrm{RH}$ using the water-swelled $D_{\mathrm{RH}}$ and water-corrected, volume-weighted refractive index $n$, as

$\sigma_{\mathrm{ext}}=\int_{4 \mathrm{~nm}}^{700 \mathrm{~nm}} \frac{\pi}{4} D_{\mathrm{RH}}^{2} \alpha\left(D_{\mathrm{RH}}, n\right) N\left(D_{\mathrm{RH}}\right) \mathrm{d} D_{\mathrm{RH}}$,

where $\alpha$ is the extinction efficiency and $N$ the number concentration of particles in diameter interval $\mathrm{d} D_{\mathrm{RH}}$.

In calculating ambient extinction using Eq. (5) it is assumed that there is no size dependence to $\kappa_{\text {chem }}$; instead it is assumed that all optically active particles are spherical, internally mixed and have the same composition regardless of size. This assumption is supported qualitatively by inspection of the size-dependent composition periodically measured by the AMS instruments. The differences in the real refractive index between the UHSAS sensing laser $(1053 \mathrm{~nm})$ and the humidified CRDS (532 nm) wavelengths of about 0.02 (Toon et al., 1976) are not considered. We also ignore the contribution of submicron soil components, which were not separately measured but whose concentrations measured at a surface site nearby were negligible (Washenfelder et al., 2015), and of sea salt, which has low concentrations in the southeastern US in summer (Guo et al., 2015).

\subsection{Uncertainty in calculated and measured extinction}

Extinctions were calculated from the measured composition and the UHSAS size distributions for the low $(\sim 15 \% \mathrm{RH})$ medium $(\sim 70 \% \mathrm{RH})$ and high $(\sim 90 \% \mathrm{RH})$ conditions of measurement in the CRDS instrument. The uncertainties in 


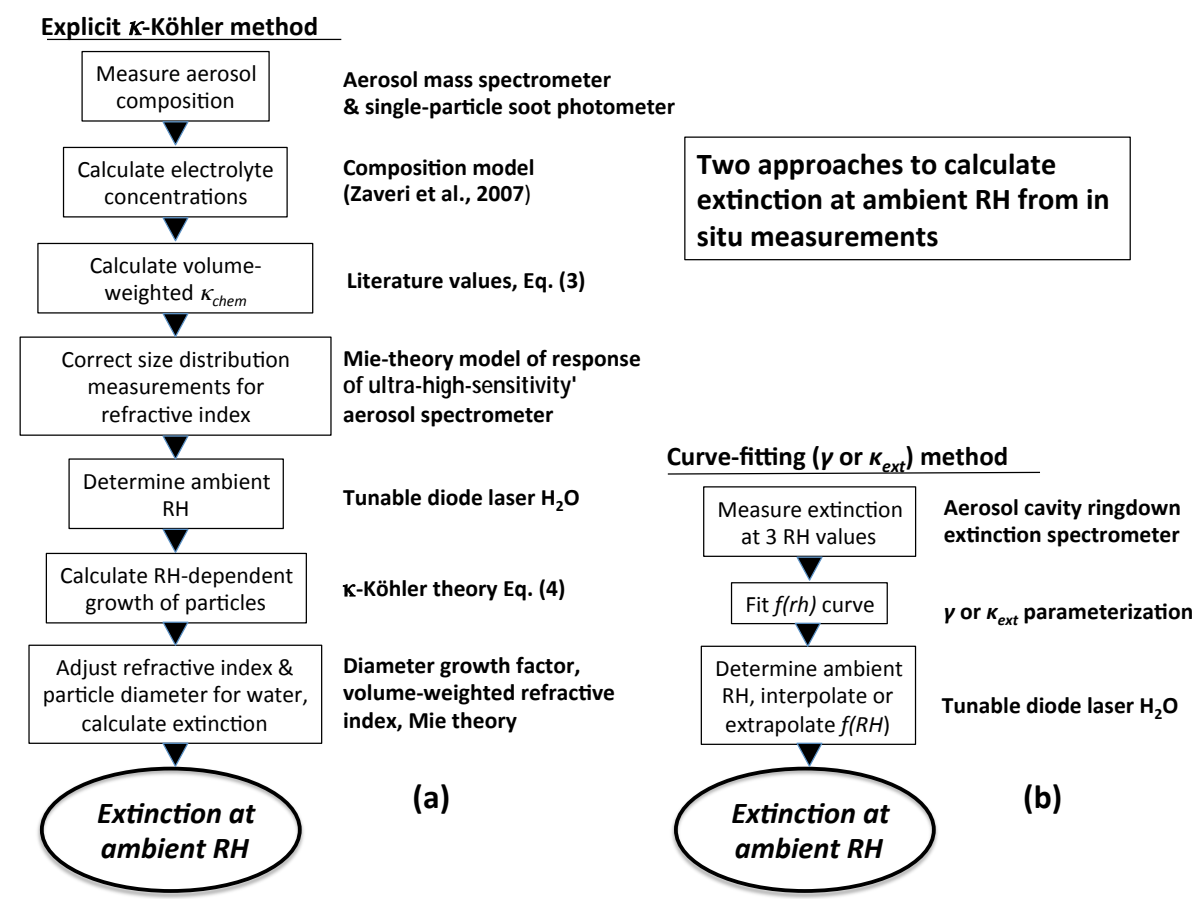

Figure 1. Schematics showing the process of calculating ambient extinction from (a) measurements of composition, size distribution, and ambient RH and (b) measurements of ambient RH and of extinction at three instrument RH values.

these extinctions are difficult to estimate because of the multiple steps of processing (Fig. 1a), including modeling the UHSAS instrument response, and the assumptions inherent in the calculation (e.g., internally mixed, homogeneous, spherical particles). We assume that $\kappa_{\text {chem }}$ for inorganic electrolytes can be estimated to within $\sim 20 \%$, based on ranges found in the cited literature. This uncertainty includes the uncertainty in the composition determined by the AMS. This uncertainty may appear low, since AMS accuracy for absolute concentrations is $\sim 35 \%$, driven in large part by uncertainties in particle collection efficiency (Middlebrook et al., 2012). However, only the mass fractions of the individual aerosol constituents are used when calculating $\kappa_{\text {chem }}$, so the collection efficiency does not contribute to the uncertainty assuming that all components of a particle are collected with the same efficiency. Instead, the uncertainty is dominated by other factors such as relative ionization efficiency for different compounds, and is taken to be $\sim 20 \%$; this uncertainty is an area of current research (Murphy, 2016). For OA, the uncertainty in the $\kappa_{\text {chem }}$ is much larger because the OA composition is largely unknown. Values of $\kappa_{\text {chem }}$ for various OA compositions measured in the laboratory vary from 0 to 0.5 (e.g., Petters and Kreidenweis, 2007; Rickards et al., 2013). To achieve consistency with the observed $f(\mathrm{RH})$, we have chosen a $\kappa_{\text {chem }}$ for OA, $\kappa_{\text {chem,OA }}$, of 0.050 . The range of $\kappa_{\text {chem,OA }}$ values that are consistent with our observations within uncertainties is discussed further in Sect. 3.3.
The uncertainty in the size distribution measured by the UHSAS has been examined in detail elsewhere (Cai et al., 2008; Brock et al., 2011). For particle diameters $<0.5 \mu \mathrm{m}$, and an assumed a range in real refractive index of 1.43-1.56 with negligible absorption, the actual diameter may deviate by up to $8 \%$ from the reported diameter, which is based on ammonium sulfate calibration. However, because we correct the size distribution for refractive index effects as described in Sect. 2.2, the error in the diameters used to calculate extinction is estimated to be $<3 \%$ based on calibration precision. Concentration uncertainty due to counting statistics is $<4 \%$ for the cases analyzed here, and that due to the sample flow measurement is $<1.6 \%$.

The uncertainties described above propagate to extinction nonlinearly through the $\kappa$-Köhler equation (Eq. 4) and through the Mie calculation (Eq. 5). We use a Monte Carlo approach to simulate the expected uncertainty in the extinction determined at the three relative humidities. Three values each of geometric mean diameter, geometric standard deviation, and $\kappa_{\text {chem }}$ were chosen spanning the interdecile range of observed values, creating a total of 27 cases. For each case, the extinction at the three RH values was calculated, as described in Sect. 2.3 (Fig. 1a), 1000 times, while median diameter, standard deviation, $\kappa_{\text {chem }}$, and $\mathrm{RH}$ each were simultaneously varied by a normally distributed random error corresponding to the uncertainty in that parameter. In addition, a normally distributed random uncertainty was added to represent counting statistics and flow uncertainty. The result- 
ing total relative errors for calculated extinction varied only slightly as a function of extinction, with a mean relative error of $\pm 34 \%$. This value is used as the best estimate of total uncertainty in calculated ambient extinction.

The calibration accuracy in directly measured CRDS extinction varies with measurement $\mathrm{RH}$, and is $\pm 2 \%$ at $\sim 15 \%$ $\mathrm{RH}, \pm 5 \%$ at $\sim 70 \% \mathrm{RH}$, and $\pm 15 \%$ at $\sim 90 \% \mathrm{RH}$ for extinction values exceeding $20 \mathrm{Mm}^{-1}$. Instrument precision for $1 \mathrm{~s}$ data is $\pm 5 \%$ at $50 \mathrm{Mm}^{-1}$.

For the seven flights analyzed for this study, the extinction calculated from the AMS and size distribution data (Sect. 2.3) and the extinction measured by the CRDS agreed within the combined experimental uncertainty at all three measurement humidities (Table 2). During the SEAC ${ }^{4} \mathrm{RS}$ flight of 6 September 2013, the UHSAS did not function, so for this flight extinction was not calculated from the composition and size distribution measurements, although the extinction values measured directly by CRDS are used.

All aerosol data used in this analysis have been corrected to conditions of $1013 \mathrm{hPa}$ and $273.15 \mathrm{~K}$. All aerosol data were measured at $1 \mathrm{~s}$ intervals, with the exception of the CToF-AMS measurements during SENEX, which were made over $10 \mathrm{~s}$ intervals. When calculating extinction from the AMS and size distributions (Fig. 1a), the SENEX data were averaged to match the C-ToF-AMS measurement frequency. The SEAC ${ }^{4} \mathrm{RS}$ data, including that from the HR-ToF-AMS, were averaged to $10 \mathrm{~s}$ to maintain statistical consistency with the SENEX data.

\section{Results and analysis}

In this section we describe the observed aerosol properties and their vertical structure, explore the relationship between particle composition and hygroscopicity, place constraints on the hygroscopicity of the OA component of the submicron aerosol, and present a new parameterization to describe the $f(\mathrm{RH})$ curve.

\subsection{Selection of data}

This analysis focuses on in situ measurements obtained during vertical profiles from the SENEX and SEAC ${ }^{4}$ RS flights made in the southeastern states of Louisiana, Mississippi, and Georgia (Fig. 2). These data were selected because they were the focus of analysis by Wagner et al. (2015) of particle vertical mixing and mass production, and because the results of this analysis and these profiles are used in a companion paper evaluating the sensitivity of AOD to several aerosol parameters and to RH (Brock et al., 2016). Wagner et al. (2015) describe in detail the selection criteria for the profiles. Briefly, profiles were included in the analysis if they were in the afternoon during fair-weather cumulus conditions, exhibited a well-mixed layer between the surface and cloud base, and contained a distinct transition (cloud) layer between the well-

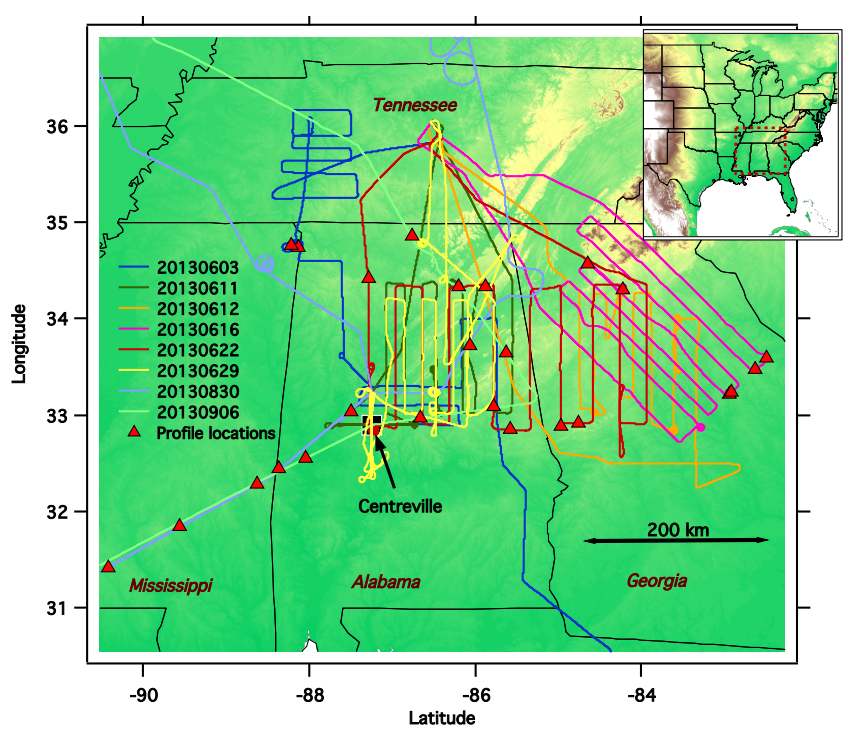

Figure 2. Map of the southeastern US showing state borders and tracks of the flights during SENEX and SEAC4RS. Triangles show the locations of the 37 vertical profiles that are used in this analysis; 25 of these had valid $f(\mathrm{RH})$ measurements. The location of the ground site in Centreville, Alabama, is indicated. The inset shows the eastern portion of the US; the dashed box indicates the sample region.

mixed layer and the free troposphere above. The well-mixed and transition layers were defined on the basis of the oxidation lifetime of the gas-phase species $\mathrm{CO}$ and isoprene. Air within the well-mixed layer was in immediate $(<1 \mathrm{~h})$ contact with surface isoprene emission, while the transition layer was evidently a result of mixing between the well-mixed layer and the free troposphere over timescales of hours.

Of the 74 profiles made in the geographic area of interest, 37 met the criteria of Wagner et al. (2015) and 25 met both the meteorological criterion and the criterion that the high-RH channel be at $\mathrm{RH}>85 \%$. The aircraft flight tracks and locations of these profiles are shown in Fig. 2. Brock et al. (2016) show that the AOD values calculated by vertically integrating the ambient extinction derived from the in situ measurements in the profiles are regionally representative and are consistent with ground-based climatologies of AOD determined from sunphotometer measurements. Thus the measurements presented here are typical of the daytime, summertime background and moderately polluted rural aerosol of this region.

\subsection{Observed aerosol composition and hygroscopicity}

Data from a single example profile measured in east-central Alabama on 22 June 2013 are shown in Fig. 3. The measured extinction at the low, medium, and high RH values (Fig. 3a), along with the RH values measured in the CRD cells and ambient air (Fig. 3b) are the fundamental measure- 
Table 2. Linear regression parameters between calculated extinction and measured extinction at $532 \mathrm{~nm}$ and three relative humidities for each flight analyzed in this work.

\begin{tabular}{|c|c|c|c|c|c|c|c|c|c|}
\hline \multirow[b]{2}{*}{ Date } & \multicolumn{3}{|c|}{ Low RH $(\sim 15 \%)$} & \multicolumn{3}{|c|}{ Medium RH $(\sim 70 \%)$} & \multicolumn{3}{|c|}{ High RH ( 90\%) } \\
\hline & $r^{2}$ & slope & intercept & $r^{2}$ & slope & intercept & $r^{2}$ & slope & intercept \\
\hline 3 Jun 2013 & $0.87^{\mathrm{a}}$ & $1.02^{\mathrm{b}}$ & -3.7 & 0.96 & 0.87 & -3.6 & 0.97 & 1.12 & -9.5 \\
\hline 11 Jun 2013 & $0.95^{\mathrm{c}}$ & 0.89 & -3.9 & & & & & & \\
\hline 12 Jun 2013 & 0.98 & 0.87 & -0.85 & 0.98 & 0.87 & -2.4 & 0.97 & 1.13 & -10.5 \\
\hline 16 Jun 2013 & 0.95 & 0.74 & 2.0 & 0.93 & 0.81 & 0.87 & 0.95 & 0.88 & 1.5 \\
\hline 22 Jun 2013 & 0.95 & 0.74 & -4.5 & 0.95 & 0.87 & -6.4 & 0.97 & 0.96 & -12.5 \\
\hline 29 Jun 2013 & 0.97 & 0.73 & -0.59 & 0.92 & 0.92 & -1.7 & 0.96 & 0.87 & -1.2 \\
\hline 30 Aug 2013 & 0.94 & 1.04 & -3.0 & 0.93 & 1.05 & -2.6 & 0.93 & 1.04 & 1.2 \\
\hline $6 \operatorname{Sep} 2013^{d}$ & & & & & & & & & \\
\hline
\end{tabular}

a $r^{2}$ values calculated from single-sided linear least squares. ${ }^{\mathrm{b}}$ Slope and intercept values calculated from orthogonal distance regression.

${ }^{\mathrm{c}}$ No humidified CRDS data available. ${ }^{\mathrm{d}}$ No UHSAS data available.

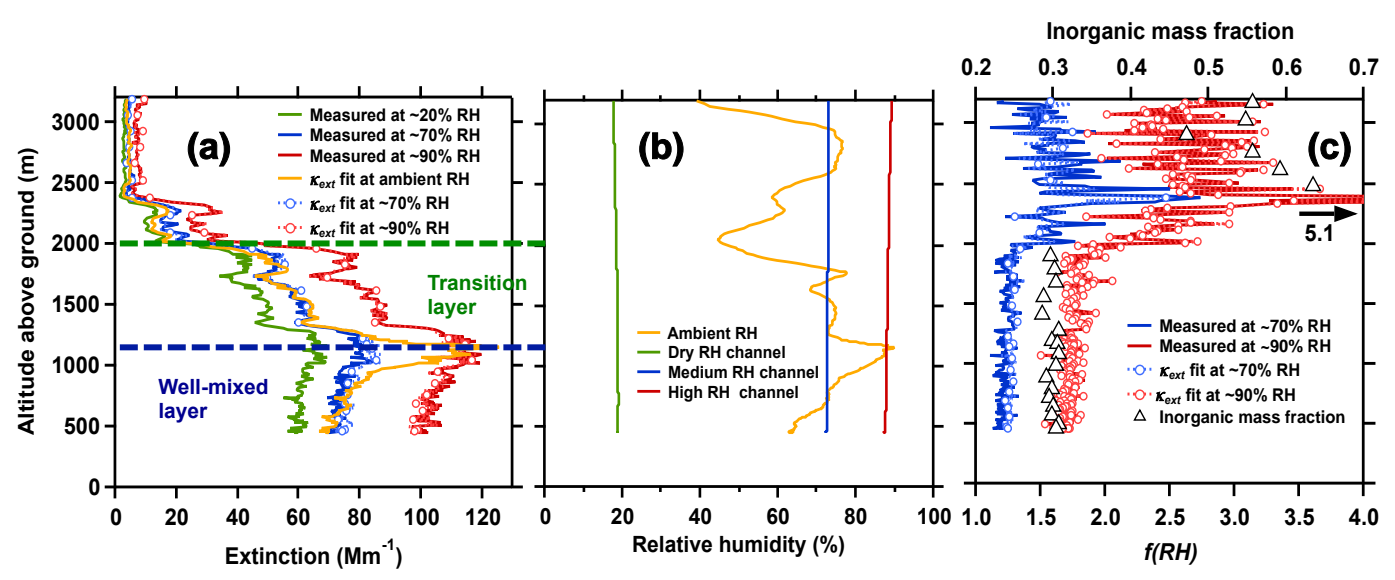

Figure 3. A vertical profile measured from 18:29 to 18:35 UTC on 22 June 2013 over east-central Alabama. (a) Extinction measured in the dry, medium-, and high-RH channels of the CRDS, extinction calculated using the fitting method described in Sect. 3.4, and extinction at ambient RH calculated using this method. The dashed horizontal lines show the boundaries between the well-mixed and transition layers and between the transition layer and free troposphere, as defined by Wagner et al. (2015). (b) Measured RH values within the dry, medium-, and high-RH channels of the CRDS, and ambient RH. (c) $f(\mathrm{RH})$ measured at the medium and high RH conditions, and calculated from fitted values as in (a). Circles show the $f(\mathrm{RH})$ values from fitting Eq. (6) to the $f(\mathrm{RH})$ data. Triangles show the fraction of sub-0.7 $\mu \mathrm{m}$ aerosol mass measured by the AMS that is inorganic (top axis).

ments. The $f(\mathrm{RH})$ values from the medium- and high-RH channels are shown in Fig. 3c. Within the well-mixed layer the dry extinction was nearly constant (Fig. 3a). The ambient $\mathrm{RH}$ reached a maximum at the top of the well-mixed layer (Fig. 3b), where the bases of the fair-weather cumulus clouds were typically found. The fraction of $\mathrm{PM}_{1}$ dry mass that was measured by the AMS to be inorganic was $\sim 0.3$ in the wellmixed and transition layers, and increased to $\sim 0.55$ in the free troposphere. Because inorganic compounds are generally more hygroscopic than are organic species (e.g., Petters and Kreidenweis, 2007), the $f(\mathrm{RH})$ at $\sim 90 \% \mathrm{RH}$ increased from $<1.7$ in the well-mixed and transition layers to $>2.5$ in the free troposphere. For comparison, the $f(\mathrm{RH})$ for pure $300 \mathrm{~nm}$ ammonium sulfate particles at $532 \mathrm{~nm}$ wavelength is expected to be $\sim 2$ at $70 \% \mathrm{RH}$ and $\sim 4$ at $90 \% \mathrm{RH}$ (Lan- gridge et al., 2011). Because the extinction and mass of the aerosol within the free troposphere was only $\sim 15 \%$ of that within the well-mixed layer, the well-mixed layer aerosol dominated aerosol composition and hygroscopicity within the transition layer.

Wagner et al. (2015) present a method to generate a composite profile while maintaining distinction between the mixed, transition, and free-tropospheric layers. Composite profiles of the subset of 25 profiles that contained valid $f(\mathrm{RH})$ data were generated by this technique (Fig. 4). As in the individual profile shown in Fig. 3, the median dry extinction was a maximum in the well-mixed layer, declined through the transition layer, and was a minimum in the free troposphere (Fig. 4a). The values of $f(\mathrm{RH})$, on the other hand, slightly increased with altitude in the well-mixed and 


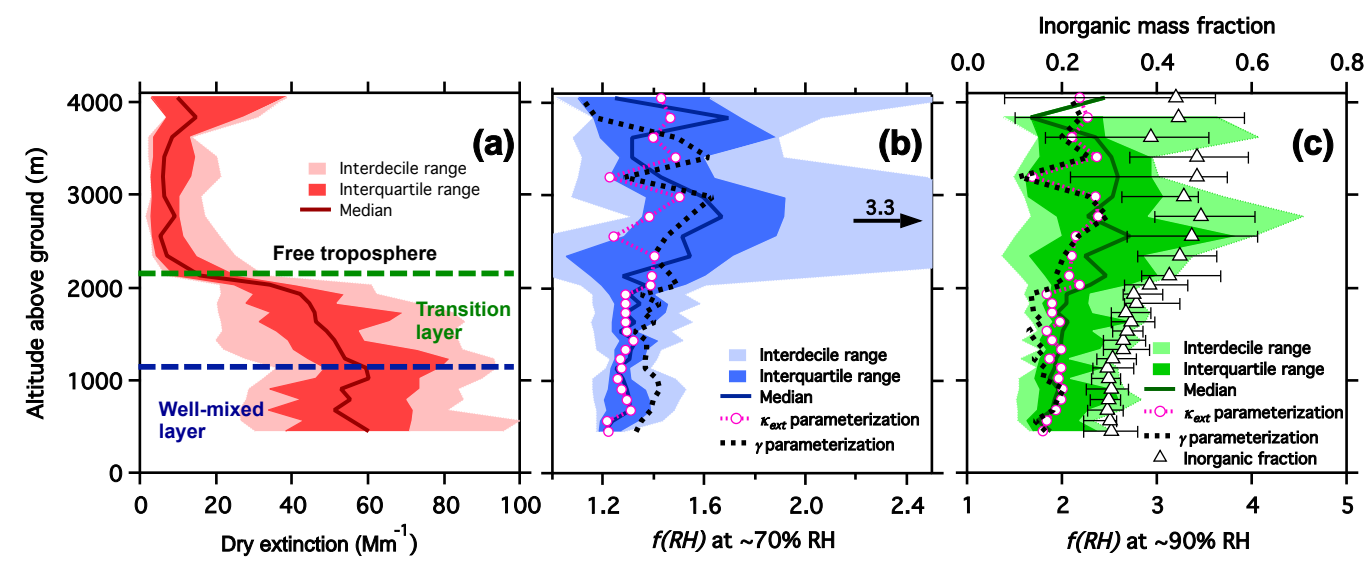

Figure 4. Composite vertical profiles of (a) dry extinction, (b) $f(\mathrm{RH})$ at $\sim 70 \% \mathrm{RH}$, and (c) $f(\mathrm{RH})$ at $\sim 90 \% \mathrm{RH}$. Shaded areas represent the interdecile and interquartile ranges. The dashed horizontal lines in (a) show the boundary between the well-mixed and transition layers and between the transition layer and free troposphere, as defined by Wagner et al. (2015). The circles and dashed lines in (b) and (c) show the mean $f(\mathrm{RH})$ values determined by fitting the $\kappa_{\text {ext }}$ and $\gamma$ parameterizations, respectively, to the raw data before altitude binning and averaging. The triangles in (c) show the fraction of sub- $0.7 \mu \mathrm{m}$ aerosol mass measured by the AMS that is inorganic (top axis); error bars show the interquartile range.

transition layers, and were a maximum in the free troposphere (Fig. $4 \mathrm{~b}, \mathrm{c})$. Values of $f(\mathrm{RH})$ were highly variable in the free troposphere, primarily because extinction values were low and signal levels were noisy. The median inorganic fraction of $\mathrm{PM}_{1}$ increased from $0.35 \pm 0.10$ averaged over the well-mixed and transition layers to $\sim 0.45$ in the free troposphere. The organic aerosol in the well-mixed layer in daytime was composed of aged secondary organic matter, primarily from biogenic sources (Kim et al., 2015; Xu et al., $2015 \mathrm{a}, \mathrm{b})$. The measured mean values of $f(\mathrm{RH})$ for all layers was $1.43 \pm 0.67$ at $\sim 70 \% \mathrm{RH}$ and $2.28 \pm 1.05$ at $\sim 90 \%$ RH.

Using the method described in Fig. 1a and Sect. 2.3, the expected extinction at the dry, $\sim 70 \%$, and $\sim 90 \% \mathrm{RH}$ conditions was calculated. The $f(\mathrm{RH})$ values from these calculated extinctions are compared with the $f(\mathrm{RH})$ values from the CRDS measurements in Fig. 5. The calculated and measured $f(\mathrm{RH})$ are in excellent agreement (slope $=1.13$, $r^{2}=0.81$ ) for the $\sim 90 \% \mathrm{RH}$ condition, but are less well correlated $\left(r^{2}=0.29\right)$ for the $\sim 70 \% \mathrm{RH}$ condition. This poorer correlation at the medium RH value may be associated with variability in organic hygroscopicity, which dominates aerosol hygroscopicity at $\mathrm{RH}<80 \%$. In Sect. 3.3 we examine the range of organic hygroscopicity that is consistent with our measurements within experimental uncertainty.

\subsection{Constraints on the hygroscopicity of $\mathrm{OA}$}

Organic matter dominated the composition of the submicron particles during both SENEX and SEAC ${ }^{4} \mathrm{RS}$, averaging $65 \pm 10 \%$ of the fine aerosol mass in the data analyzed here (Sect. 3.1). Published values for the hygroscopic growth parameter of OA, $\kappa_{\text {chem, OA }}$, vary widely between $\sim 0$ and
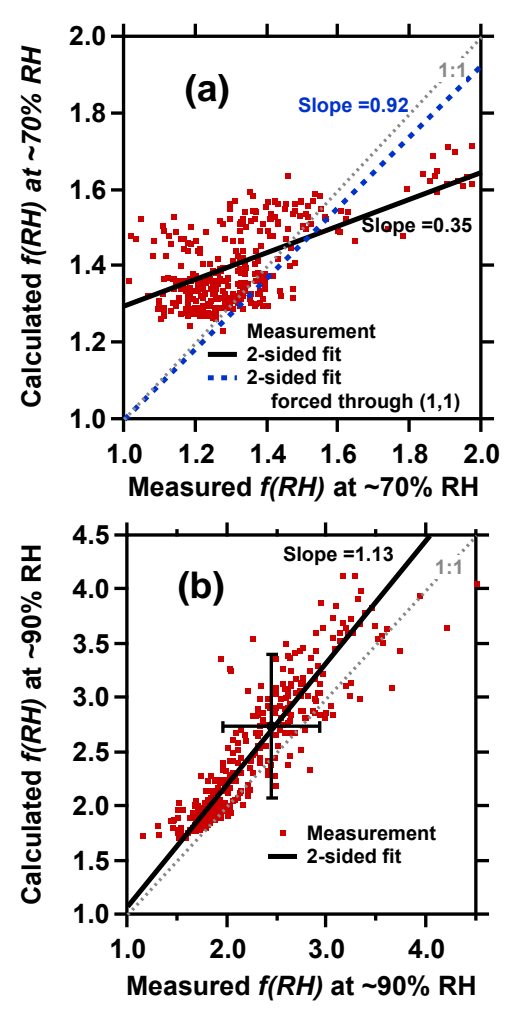

Figure 5. (a) Calculated $f(\mathrm{RH})$ compared with observed $f(\mathrm{RH})$ at $\sim 70 \%$ RH using the methodology in Fig. 1a for all analyzed data. Lines are two-sided least-squares (orthogonal distance regression) fits to the data. The dashed line is calculated assuming the line passes through $(1,1)$. (b) As in (a), but for $~ 90 \%$ RH. Organic hygroscopicity $\left(\kappa_{\text {chem,OA }}\right)$ is assumed to be 0.05 . 
0.4 (e.g., Petters and Kreidenweis, 2007; Rickards et al., 2013; Suda et al., 2012). A parameterization linking $\kappa_{\text {chem,OA }}$ to the ratio of the oxidized OA fragment $\mathrm{m} / \mathrm{z} 44$ to total OA mass $\left(f_{44}\right)$ as measured in the AMS has been developed (Duplissy et al., 2011). However, Rickards et al. (2013) find that this parameterization does not fit many available data, and that significant variations in aerosol chemical functionality, composition, and oxidation history affect $\kappa_{\text {chem,OA }}$. Cerully et al. (2015) show that, in the southeastern US, $\kappa_{\mathrm{chem}, \mathrm{OA}}$ is not simply related to oxidation level, but to additional parameters including OA volatility. Values of $\kappa_{\text {chem }}$ for atmospheric aerosols are commonly determined experimentally using measurements of droplet activation diameter in the supersaturated regime (e.g., Cerully et al., 2015; Chang et al., 2010; Dusek et al., 2010; Gunthe et al., 2009; Levin et al., 2012; Sihto et al., 2011) or using hygroscopic growth measurements in the subsaturated regime (Cappa et al., 2011; Cheung et al., 2015; Hersey et al., 2013; Malm et al., 2000; Mikhailov et al., 2013; Nguyen et al., 2014; Sihto et al., 2011). Atmospheric variability in these measurements is compounded by potential measurement artifacts (Good et al., 2010b). Although not always explicitly calculated, the value of $\kappa_{\text {chem,OA }}$ often can be inferred from these studies. A review of results from the publications cited above suggests a range of mass-weighted total $\kappa_{\text {chem,OA }}$ from 0 to 0.2 well represents the organic hygroscopicity of the ambient aerosol in a variety of environments, with best estimates of $<0.1$ for subsaturated (hygroscopic growth) measurements and $>0.1$ for supersaturated $(\mathrm{CCN})$ measurements.

Given the high organic fraction of the aerosol, the value of $\kappa_{\text {chem, }} \mathrm{OA}$ is an important factor determining observed $f(\mathrm{RH})$. We can examine which values of $\kappa_{\text {chem, OA }}$ are consistent with our measurements within experimental uncertainty to place constraints on this parameter. Some of the errors in the calculated extinction - UHSAS sizing bias, UHSAS counting statistics, and UHSAS and AMS flow uncertainties (Sect. 2.4) - are not independent and should cancel when calculating $f(\mathrm{RH})$. Ignoring these error terms, relative errors in calculated $f(\mathrm{RH})_{70}$ of $\pm 7 \%$ and in $f(\mathrm{RH})_{90}$ of $\pm 24 \%$ were determined using the Monte Carlo method described in Sect. 2.4. To calculate the range in $\kappa_{\text {chem,OA }}$ that was consistent with the observed $f(\mathrm{RH})_{70}$ and $f(\mathrm{RH})_{90}$, the following approach was used. (1) For each measurement point, the inorganic $\kappa_{\text {chem }}$ determined from the AMS measurements was held constant. (2) A Monte Carlo simulation assigned a random $\kappa_{\text {chem,org }}$ between 0.0 and 0.5 , and the values of $f(\mathrm{RH})_{70}$ and $f(\mathrm{RH})_{90}$ were calculated. (3) When the calculated $f(\mathrm{RH})_{70}$ and $f(\mathrm{RH})_{90}$ both agreed with the measured values within their uncertainties, the value of $\kappa_{\mathrm{chem}, \mathrm{OA}}$ was recorded; otherwise step (2) was repeated. This process was repeated 50 times for each data point, and the mean value of each $\kappa_{\text {chem,OA }}$ that was consistent with the data was recorded. Thus statistics were built for the values of $\kappa_{\text {chem,OA }}$ that were consistent with observed hygroscopic growth at both the high and medium RH conditions.

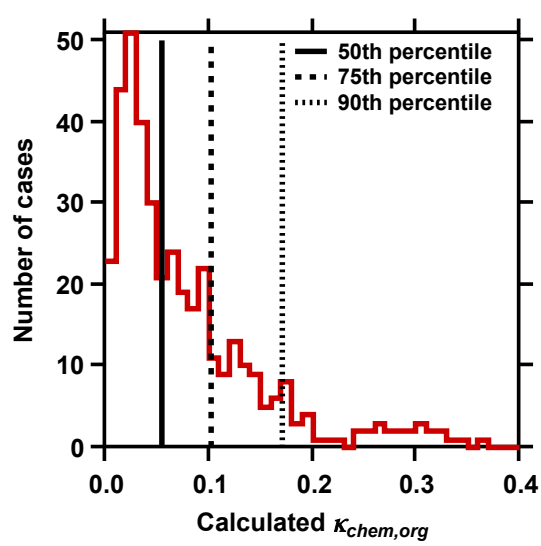

Figure 6. Histogram of results from a Monte Carlo analysis showing values of the organic $\kappa_{\text {chem }}$ that, given the observed inorganic composition and size distribution, are consistent within experimental uncertainty with the measured $f(\mathrm{RH})$. Vertical lines indicate the 50th, 75th, and 90th percentile values of the histogram.

A histogram of the values of mean $\kappa_{\text {chem,OA }}$ that were consistent with the $f(\mathrm{RH})$ observations within uncertainty (Fig. 6) is heavily skewed toward zero, with the 50th, 75th, and 90th percentile values being $0.05,0.10$, and 0.17 , respectively. This outcome demonstrates that a low value of $\kappa_{\text {chem,OA }}$ is necessary to match the observed $f(\mathrm{RH})$ values, with a best estimate of 0.05 . Only values of $\kappa_{\text {chem,OA }}<0.10$ can be consistent with the relatively small increase in $f(\mathrm{RH})$ at the medium RH value of $\sim 70 \%$ (Fig. 7a) in most (75\%) of our data. Our analysis assumes a homogeneous, sizeindependent internal mixture of the aerosol components, and does not account for the possible presence of sparingly soluble OA compounds (Wex et al., 2009) or for the diameter dependence of $\kappa_{\text {chem }}$ (Good et al., 2010a). Nguyen et al. (2014) suggest that $\kappa_{\text {chem }}$ itself is a function of RH due to an increasing osmotic coefficient with decreasing $\mathrm{RH}$. We find that a single, constant $\kappa_{\text {chem }}$ explains the $f(\mathrm{RH})$ at $90 \% \mathrm{RH}$, but only if $\kappa_{\text {chem, }, \mathrm{OA}}$ is $<0.10$ for $>75 \%$ of our data.

\subsection{Parameterizing $f(\mathrm{RH})$}

The hygroscopic growth of particles and $f(\mathrm{RH})$ can be calculated using the technique shown in Fig. 1a and Table 2 if discrete phase transitions can be ignored. However, a simplified parameterization based on optical measurements alone (Fig. 1b) is useful when compositional or size distribution observations are not available, as is often the case for in situ data from monitoring networks or measurements from mobile platforms. The often-used $\gamma$ parameterization (Eq. 1) has the desired simplicity. In Fig. 7a we plot the observed $f(\mathrm{RH})$ found within the well-mixed layer in the single profile in Fig. 3. The $\gamma$ parameterization with $\mathrm{RH}_{0}=0$ did not match within uncertainties the $f(\mathrm{RH})$ directly observed by the medium-RH channel of the CRDS. This bias at $\sim 70 \%$ $\mathrm{RH}$ occurred frequently, as shown in the composite profiles 

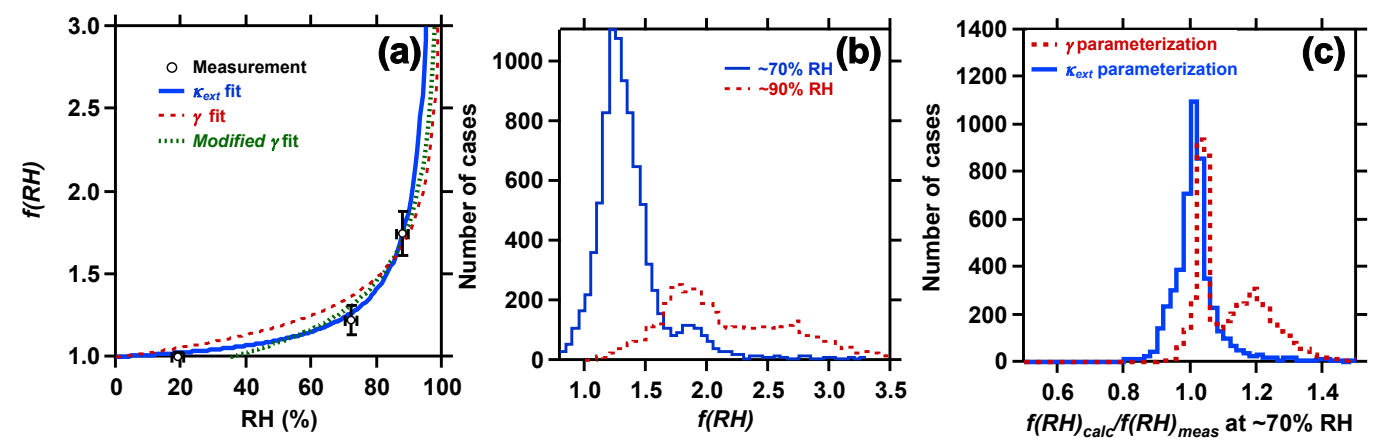

Figure 7. (a) Mean values of $f(\mathrm{RH})$ determined profile data in the well-mixed and transition layers (below $2000 \mathrm{~m}$ altitude) on 22 June 2013 over central Alabama from Fig. $3 \mathrm{c}$ (symbols), and curves from the $\gamma$ power-law parameterization (dashed line, Eq. 1$)$ and the $\kappa_{\mathrm{ext}}$ parameterization (solid line, Eq. 6) fitted to the three data points. The green dashed line shows a fit to the $\gamma$ parameterization assuming $\mathrm{RH}_{0}=35 \%$ (see Sect. 3.4). Error bars show the propagated measurement uncertainties and measurement standard deviation. (b) Histograms of values of $f(\mathrm{RH})$ measured at medium RH (70 $\pm 3 \%)$ and at high RH (86-94\%) for all of the data selected for this study. (c) Ratio of calculated to measured $f(\mathrm{RH})$ at $\sim 70 \% \mathrm{RH}$ for the $\gamma$ and $\kappa_{\text {ext }}$ parameterizations for all of the data selected for this study.

(Fig. 4b) and in histogram form (Fig. 7c). The planetary boundary layer in the southeastern US is often at humidities between 50 and $90 \%$ where the $\gamma$ parameterization could lead to overprediction of the ambient extinction by $20 \%$ or more. Because of these biases we have sought a different single-parameter representation of the $f(\mathrm{RH})$ curve.

In the Appendix, we use $\kappa$-Köhler and Mie theories to develop an alternative parameterization for $f(\mathrm{RH})$. This parameterization is given by

$f(\mathrm{RH}) \cong 1+\kappa_{\mathrm{ext}} \frac{\mathrm{RH}}{100-\mathrm{RH}}$,

where $\kappa_{\text {ext }}$ is the fitted parameter. When fitted to the threepoint $f(\mathrm{RH})$ measurements in SENEX and $\mathrm{SEAC}^{4} \mathrm{RS}$, both the $\kappa_{\text {ext }}$ and $\gamma$ parameterizations fit the high $\mathrm{RH}$ condition well (Figs. 4c, 7a). However, the $\kappa_{\text {ext }}$ parameterization predicts the medium-RH extinction values better than does the $\gamma$ parameterization for most of the data (Figs. 4b, 7a). In 17 of the 25 profiles for which valid hygroscopicity measurements were made, the $\kappa_{\text {ext }}$ parameterization described the observed hygroscopic growth better than did the $\gamma$ parameterization, as determined by a $\chi^{2}$ statistic. This improved performance is shown Fig. 7c, where the fitted and measured $f(\mathrm{RH})$ values at the medium $(70 \%) \mathrm{RH}$ condition for the two parameterizations are compared. The ratio of fitted to measured $f(\mathrm{RH})$ values at $70 \% \mathrm{RH}$ for $\kappa_{\mathrm{ext}}$ is centered near 1 and is symmetric, while that for $\gamma$ is $>1$ for most of the data. Further, there are distinct differences in the fitted $f(\mathrm{RH})$ curves for the two approaches for RH $>90 \%$, with the $\kappa_{\text {ext }}$ parameterization showing a more rapid increase in $f(\mathrm{RH})$ with increasing RH for these high-humidity conditions (Fig. 7a). Preliminary evaluation of ambient atmospheric data acquired in February 2015 in Boulder, Colorado, US (Appendix), provides an example where the $\kappa_{\text {ext }}$ curve more closely follows the observed $f(\mathrm{RH})$ for ambient particles at $\mathrm{RH}>90 \%$ than does the $\gamma$ parameterization. In the Supplement we also present additional analysis of data from the work of Zieger et al. (2013) that support the use of the $\kappa_{\text {ext }}$ parameterization (Eq. 6) in polluted and background continental cases where organic aerosol matter is likely to be a dominant component.

The $\gamma$ parameterization (Eq. 1) is sometimes used with $\mathrm{RH}_{0}$ set to some value other than 0 , which is used here. In this application, $f(\mathrm{RH})$ is assumed to be zero for $\mathrm{RH} \leq \mathrm{RH}_{0}$, then increases sharply for $\mathrm{RH}>\mathrm{RH}_{0}$. That approach may produce a better fit to the measured $f(\mathrm{RH})$ values (e.g., Fig. 3a), but is probably most suitable for aerosols dominated by inorganic constituents which exhibit sharp deliquescence features. This approach is not appropriate for the continuous hygroscopic growth expected for the organic-dominated aerosols found in the southeastern US, and in particular for the deliquesced $f(\mathrm{RH})$ curve measured by the CRDS system.

In the Appendix we examine the relationship between $\kappa_{\text {ext }}$ determined from fitting the $f(\mathrm{RH})$ values (Eq. 6) and $\kappa_{\text {chem }}$ calculated from particle composition measurements (Eq. 3). These parameters are related but not identical.

\subsection{Comparison of airborne and ground-based data}

The airborne data can be compared with contemporaneous measurements at the SOAS ground site in Centreville of the change in $\sigma_{\text {ext }}$ at wavelengths of 360-420 nm at two RH values (Attwood et al., 2014). Wagner et al. (2015) show that the airborne data measured in the well-mixed afternoon boundary layer near the Centreville site agree well with the surface measurements. Attwood et al. (2014) fit the ground site data using the $\gamma$ parameterization (Eq. 1) and find a decrease in hygroscopicity with increasing OA mass fraction that is consistent with earlier studies in different aerosol types. Using the $f(\mathrm{RH})$ measurements by Attwood et al. (2014) and solving Eq. (6), $\kappa_{\text {ext }}$ can be calculated and compared with the airborne data. These values are plotted in Fig. 8 against the fraction of the total submicron non-refractory OA mass (note 


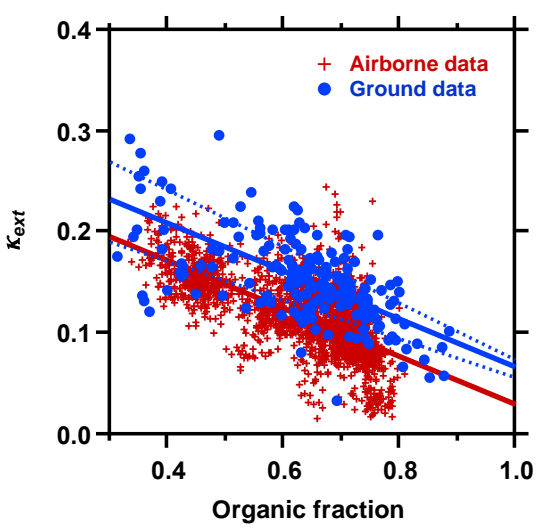

Figure 8. Comparison of $\kappa_{\mathrm{ext}}$ as a function of the fraction of sub- $0.7 \mu \mathrm{m}$ non-refractory OA for the data analyzed in this paper (crosses) and similar measurements at the SOAS ground site in Centreville, Alabama, US (Washenfelder et al., 2015), between the hours of 11:00 and 17:00 local time (circles).

that this differs slightly from the $F_{\text {oa }}$ parameter reported by Attwood et al., 2014), as measured by a HR-ToF-AMS at the Centreville site (Xu et al., 2015a, b). Also plotted are the values from the airborne data used in this analysis, restricted to AMS mass concentrations $>8 \mu \mathrm{g} \mathrm{m}^{-3}$ to compare boundary layer air only. The airborne and ground data are similar, with slopes of $-0.24 \pm 0.01$ and $-0.24 \pm 0.04$, respectively (95\% confidence intervals). The $\kappa_{\text {ext }}$ values from the ground site are higher; however, the $\kappa_{\text {ext }}$ determined from a two-point $f(\mathrm{RH})$ measurement is particularly sensitive to the accuracy of the RH measurements in the extinction cell, as shown by the dashed lines in Fig. 8, which represent the variation in $\kappa_{\text {ext }}$ due to the stated absolute uncertainty in the RH measurement at the ground site of $\pm 3 \%$. Extrapolating the central fits to an OA fraction of 1 yields a $\kappa_{\text {ext }}$ of 0.030 for the airborne data and 0.067 for the data from the ground site. The ratio of $\kappa_{\text {ext }}$ to $\kappa_{\text {chem }}$ is expected to be $\sim 0.5$ to 1 for typical accumulation-mode size distributions (Appendix), so a value of $\kappa_{\text {chem,OA }}$ of $\sim 0.07-0.14$ would be expected at the SOAS ground site. These values are generally consistent with the airborne results showing a relatively low value of $\kappa_{\text {chem, OA }}$ $(<0.10$ for $75 \%$ of the data).

\section{Discussion and conclusions}

The submicron aerosol observed in typical summertime, fairweather, afternoon conditions in the southeastern US displayed a vertical structure of a well-mixed layer between the surface and $\sim 1100 \mathrm{~m}$ above the surface, a transition layer from $\sim 1100$ to $\sim 2100 \mathrm{~m}$, and the free troposphere above $\sim 2100 \mathrm{~m}$. Wagner et al. (2015) more fully describe this vertical structure and the gas-phase and aerosol characteristics of each layer, and show that ammonium and sulfate were the dominant inorganic aerosol constituents in all the lay- ers. Within the well-mixed layer, the aerosol was $\sim 65 \% \mathrm{OA}$, and declined to $\sim 50 \% \mathrm{OA}$ in the free troposphere. As a result of this composition, the aerosol on average was modestly hygroscopic, with $f(\mathrm{RH})=1.43 \pm 0.67$ at $\sim 70 \% \mathrm{RH}$ and $2.28 \pm 1.05$ at $\sim 90 \% \mathrm{RH}$. Ammonium sulfate exhibits an $f(\mathrm{RH})$ of $\sim 2$ at $\sim 70 \% \mathrm{RH}$ (Langridge et al., 2011), attesting to the low hygroscopicity of the OA component.

The hygroscopicity of OA varies with level of oxidation ( $\mathrm{O}: \mathrm{C}$ ratio), oxidation state, and solubility, among other parameters (e.g., Cappa et al., 2011; Cerully et al., 2015; Duplissy et al., 2011; Rickards et al., 2013). The large number of possible OA sources, oxidation histories, and compositions suggests a broad range of OA hygroscopicities. While the slope of the least-squares fit between the calculated and measured $f(\mathrm{RH})$ values at $\sim 70 \% \mathrm{RH}$ is 0.35 , the $r^{2}$ value is only 0.43 and most of the data cluster near the $1: 1$ line; the low slope and poor correlation are driven by a small number of points. At $\sim 90 \% \mathrm{RH}$, the calculated and measured $f(\mathrm{RH})$ are in excellent agreement and are well correlated (Fig. 5b). This agreement at $\sim 90 \% \mathrm{RH}$, where the signal-to-noise ratio in the $f(\mathrm{RH})$ measurement is high, precludes a high value of $\kappa_{\text {chem,OA. }}$. For $>75 \%$ of the data, a value of $\kappa_{\text {chem, OA }}<0.1$ represents a reasonable upper bound on subsaturated OA hygroscopicity in this environment.

The value of $\kappa_{\text {chem,OA }}<0.1$ is broadly consistent with most previous work measuring atmospheric aerosol hygroscopicity in the subsaturated regime (Cheung et al., 2015; Hersey et al., 2013; Mikhailov et al., 2013; Nguyen et al., 2014; Sihto et al., 2011). Many chemistry-climate models use $\kappa$-Köhler theory to predict the hygroscopic growth and ambient radiative properties of the aerosol (e.g., Liu et al., 2012). Because OA is a substantial component of the aerosol in many environments (Zhang et al., 2007), it should be a priority to use atmospheric measurements to continue to improve understanding of the factors that control OA hygroscopicity and to evaluate the extent to which the findings reported here apply to other organic-rich environments. Further, the variation in composition and hygroscopicity as a function of particle size, which we ignore here, should be examined more thoroughly. As shown by Zieger et al. (2010), particle size and hygroscopicity can have compensating effects; for example, smaller and less hygroscopic particles (e.g., dominated by organics) can have the same $f(\mathrm{RH})$ as larger and more hygroscopic particles (e.g., sea spray).

Finally, the $\gamma$ power-law parameterization, which is widely used to describe $f(\mathrm{RH})$ for atmospheric aerosols, did not effectively replicate many of the observations of $f(\mathrm{RH})$ in this environment, primarily because actual hygroscopic growth was lower than parameterized growth at $70 \% \mathrm{RH}$. An alternative parameterization based on $\kappa$-Köhler theory was developed and found to better describe the observed $f(\mathrm{RH})$ in the southeastern US in summer. This $\kappa_{\text {ext }}$ parameterization may be applicable to background and moderately polluted cases where the extinction is dominated by organic particles with diameters $<0.7 \mu \mathrm{m}$. 


\section{Appendix A}

\section{A1 Derivation of the $\kappa_{\text {ext }}$ parameterization}

The cube of the diameter growth factor $\mathrm{gf}_{\text {diam }}$ (Eq. 2) is the volume growth factor. Relating the volume growth factor to bulk $f(\mathrm{RH})$, however, involves the complicated variation of aerosol extinction efficiency as a function of particle diameter, often described using Mie theory. As particles grow due to water uptake as RH increases, the extinction cross section can change nonlinearly, and can even decrease (e.g., Bohren and Huffman, 1983). However, as pointed out earlier (Chylek, 1978; Pinnick et al., 1980), for a physically realistic, polydisperse aerosol composed of particles predominantly smaller than the wavelength of light (but larger than Rayleigh scatterers), $\sigma_{\text {ext }}$ is roughly proportional to integrated particle volume or mass. This proportionality results because the extinction efficiency $\alpha\left(D_{\mathrm{p}}, n\right)$ for visible light can be approximated as a linear function of particle diameter over the relatively broad size range of a polydisperse accumulation-mode atmospheric aerosol (i.e., $\alpha$ is proportional to $D_{\mathrm{p}}$, Fig. A1). It then follows from Eq. (5) that $\sigma_{\text {ext }} \propto D_{\mathrm{p}}^{3}$ : extinction is proportional to volume. Thus the relative change in extinction, $f(\mathrm{RH})$, is roughly proportional to the relative change in volume, which for the case of a deliquescing aerosol is the volume growth factor $\mathrm{gf}_{\mathrm{vol}}$. The approximate proportionality between extinction and volume is valid for particles smaller than the wavelength of light, which for these measurements is $532 \mathrm{~nm}$. The 10th to 90th percentile range for the geometric median diameters considered here was $120-170 \mathrm{~nm}$, so this approximation is valid, even for particles at high RH. The approximate (no Kelvin effect) diameter growth factor from $\kappa$-Köhler theory is given in Eq. (2). The cube of this is then roughly proportional to $\mathrm{gf}_{\mathrm{vol}}$ and $f(\mathrm{RH})$ :

$\mathrm{gf}_{\mathrm{vol}} \propto f(\mathrm{RH}) \cong 1+\kappa_{\mathrm{ext}} \frac{\mathrm{RH}}{100-\mathrm{RH}}$,

where $\kappa_{\text {ext }}$ is a dimensionless parameter fitted to observed $f(\mathrm{RH})$.

The volume-extinction approximate proportionality in Eq. (A1) applies for an aerosol of constant refractive index, which is not the case for an atmospheric aerosol particle growing by addition of water with increasing RH (Hänel, 1976; Hegg et al., 1993). The methodology to calculate ambient extinction (Sect. 2.3), which incorporates the aerosol composition and size distribution measurements, can be used to estimate the effect of aerosol water on the refractive index and its impact on extinction. Using this approach, the calculated mean decrease in refractive index caused by condensed water reduces extinction by a factor of $0.81 \pm 0.03$ for the $\sim 70 \% \mathrm{RH}$ channel and by $0.71 \pm 0.03$ for the $\sim 90 \% \mathrm{RH}$ channel. Because of this effect and the rough proportionality between particle volume and extinction, Eq. (A1) is only an approximation that should be used parametrically to interpolate and extrapolate from discrete measurements on the

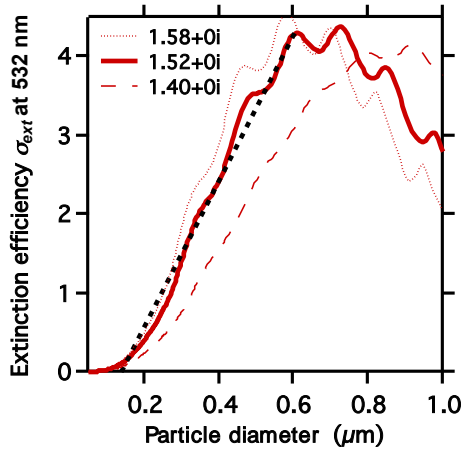

Figure A1. Calculated extinction efficiency for a particle with a refractive index of $1.52+0 i$ (solid line) and linear least-squares fit for $0.1<D_{\mathrm{p}}<0.6$ (dashed line). The extinction efficiency averaged across the size range of hygroscopic growth of a typical accumulation-mode aerosol is approximately linear. Extinction efficiency curves for $1.58+0 i$ and $1.40+0 i$ are also shown.

$f(\mathrm{RH})$ curve. However, it is a physically based representation of the expected functional form of $f(\mathrm{RH})$, unlike alternative parameterizations.

We caution that, like the $\gamma$ parameterization, the $\kappa_{\text {ext }}$ parameterization may not accurately describe $f(\mathrm{RH})$ in many circumstances. For example, the abrupt phase transitions of inorganic salts sometimes observed in the atmosphere (e.g., Santarpia et al., 2005) clearly cannot be described by this smooth function (nor by the $\gamma$ parameterization). More complex, multi-parameter descriptions of aerosol deliquescence and efflorescence (e.g., Kotchenruther et al., 1999; Mikhailov et al., 2013; Zieger et al., 2011) are underconstrained by our three-point $f(\mathrm{RH})$ deliquescence measurement. Further, the hygroscopic growth of aerosols dominated by larger particles, such as sea salt, dust, and primary plant materials is unlikely to follow the $\kappa_{\text {ext }}$ parameterization because the midvisible extinction efficiency for particles larger than $0.6 \mu \mathrm{m}$ does not monotonically increase (Fig. A1). However, for a broad range of typical aged continental aerosol size distributions and organic-rich compositions ranging from background to moderately polluted, from the boundary layer to the free troposphere, the $\kappa_{\text {ext }}$ parameterization may effectively describe the $f(\mathrm{RH})$ curve for the deliquesced aerosol. Further examples from the literature are presented in the Supplement, and Sect. A3 provides additional data from wintertime rooftop measurements supporting the use of the $\kappa_{\text {ext }}$ parameterization.

\section{A2 Relationship between $\kappa_{\text {chem }}$ and $\kappa_{\text {ext }}$}

Equations (2) and (A1), which define $\kappa_{\text {chem }}$ and $\kappa_{\text {ext }}$, are of similar form, but the $f(\mathrm{RH})$ term in Eq. (A1) incorporates aerosol extinction, which is a complex function of the particle size distribution and refractive index (Fig. A1). We use a size distribution and Mie scattering model to examine the relationship between $\kappa_{\mathrm{chem}}$ and $\kappa_{\mathrm{ext}}$. The aerosol was repre- 


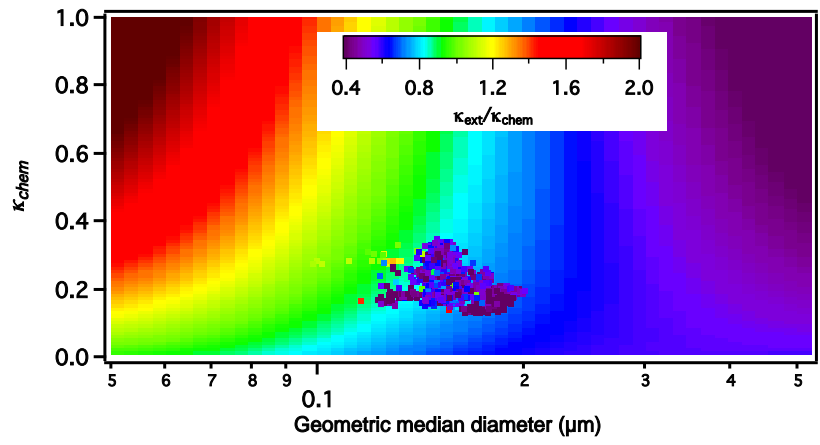

Figure A2. Ratio of optically determined $\kappa_{\text {ext }}$ to chemically determined $\kappa_{\text {chem }}$ as a function of particle geometric median diameter and $\kappa_{\text {chem }}$. Values of $\kappa_{\text {ext }}$ were calculated for a lognormal particle size distribution with a geometric standard deviation of 1.5 and a geometric median diameter given by the abscissa. Points are instantaneous values of $\kappa_{\text {ext }} / \kappa_{\text {chem }}$ determined from the in situ $f(\mathrm{RH})$ and composition measurements.

sented as a single-mode lognormal size distribution with a fixed geometric standard deviation of 1.5; the observed interdecile range for the data analyzed here was $1.42-1.60$. The geometric mean diameter was varied from 0.04 to $0.5 \mu \mathrm{m}$ and the $\kappa_{\text {chem }}$ value was varied from 0 to 1 . The dry refractive index was fixed at $1.53+0 i$. At each geometric mean diameter and each value of $\kappa_{\text {chem }}$, the water uptake was determined at 10,70 , and $90 \% \mathrm{RH}$, which approximately matched the measurement $\mathrm{RH}$ values for the low, medium and high CRDS channels, and the extinction from the deliquesced size distribution was calculated. After determining the extinction at all three RH levels, Eq. (A1) was fitted to the calculated $f(\mathrm{RH})$ values to determine $\kappa_{\text {ext }}$. Thus the chemically derived $\kappa_{\text {chem }}$ could be compared with the optically derived $\kappa_{\text {ext }}$ over a range of median particle diameters and $\kappa_{\text {chem }}$ values. As shown in Fig. A2, the ratio of $\kappa_{\text {ext }} / \kappa_{\text {chem }}$ varied from $<0.4$ to $>2.0$ over this range of modal diameters and $\kappa_{\text {chem }}$ values. However, for the range of $\kappa_{\text {chem }}$ values of $\sim 0.1$ to $\sim 0.4$ and the geometric mean diameter range from $\sim 0.1$ to $\sim 0.2$, approximately matching the ranges observed in the southeastern US (Cerully et al., 2015), the $\kappa_{\text {ext }} / \kappa_{\text {chem }}$ ratio generally lies between 0.6 and 1.0. Thus $\kappa_{\text {ext }}$ and $\kappa_{\text {chem }}$ are expected to be roughly equivalent in magnitude, with $\kappa_{\text {ext }}$ tending toward smaller values, and to vary approximately proportionally (i.e., the value of $\kappa_{\text {ext }} / \kappa_{\text {chem }}$ does not change much with changing $\kappa_{\mathrm{chem}}$ ).

The $\kappa_{\text {ext }} / \kappa_{\text {chem }}$ ratio from the simulation described above can be compared with the same ratio determined from the airborne extinction and aerosol composition measurements, also shown in Fig. A2. The measured mean $\kappa_{\text {ext }} / \kappa_{\text {chem }}$ was 0.52 , with considerable dispersion. This ratio is lower than that expected from the simple single-mode lognormal model. This difference may arise because the atmospheric size distribution is not purely lognormal, and the magnitude of the modeled $\kappa_{\text {ext }} / \kappa_{\text {chem }}$ shown in Fig. A2 (i.e., the color scale)

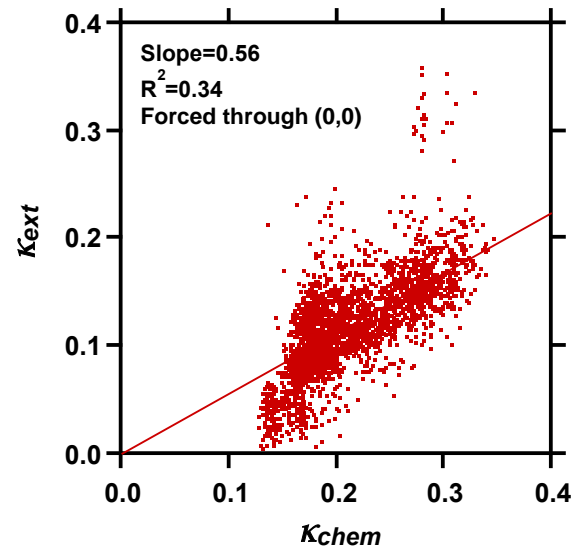

Figure A3. Values of $\kappa_{\text {ext }}$ determined from fitting Eq. (6) to the $f(\mathrm{RH})$ data plotted as a function of $\kappa_{\text {chem }}$ calculated from aerosol composition measurements using $\kappa$-Köhler theory (Eq. 3).

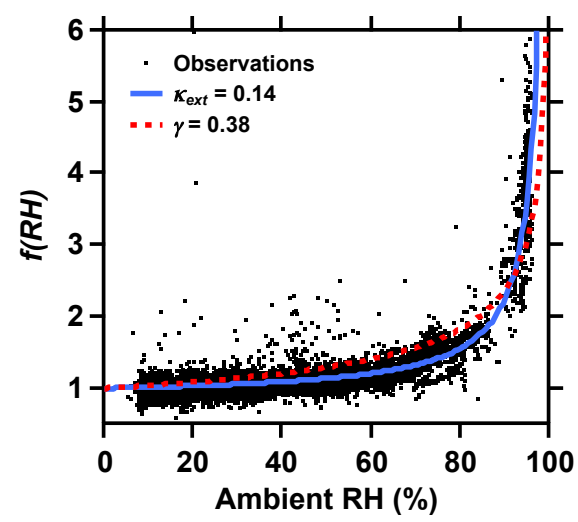

Figure A4. Values of $f(\mathrm{RH})$ from rooftop measurements of ambient and dry extinction made at Boulder, Colorado, US, from 5 March to 6 April 2015. Curves are two-sided least-squares fits to the data using the $\kappa_{\text {ext }}$ and $\gamma$ parameterizations. Data are selected for periods when $\kappa_{\text {chem }}$ determined from measurements made with the C-ToF-AMS were $<0.4$.

is sensitive to the assumed geometric standard deviation (although the overall shape of the pattern is not). Over the course of the measurements, $\kappa_{\mathrm{ext}}$ and $\kappa_{\mathrm{chem}}$ were correlated (Fig. A3). The relationships were more linear and with less dispersion for individual flights than for the data set as a whole, suggesting day-to-day variability in mean size distribution, composition, and/or instrument performance. These data emphasize that $\kappa_{\text {ext }}$ and $\kappa_{\text {chem }}$ are related but substantially different parameters, coupled nonlinearly by Mie theory and the particle size distribution function, and cannot be substituted directly for one another. 


\section{A3 Additional data supporting use of the $\kappa_{\text {ext }}$ parameterization}

The data presented in this manuscript show $f(\mathrm{RH})$ at only three RH values in the summertime, background aerosol of the southeastern US. To provide evidence of the broader applicability of the $\kappa_{\text {ext }}$ parameterization, in this section we present additional measurements of $f(\mathrm{RH})$ obtained over a wide range of ambient $\mathrm{RH}$ values in a different environment. Data were obtained from an open-path cavity ringdown spectrometer (OP-CRDS; Gordon et al., 2015), which measured extinction at ambient conditions at a suburban rooftop site, the NOAA Earth System Research Laboratory in Boulder, Colorado. The aircraft CRDS system was used to provide a dry extinction value at $\mathrm{RH}<10 \%$ for calculating $f(\mathrm{RH})$. An $f(\mathrm{RH})$ curve was obtained as the ambient $\mathrm{RH}$ varied due to changing meteorological conditions. The same C-ToF-AMS flown during SENEX measured simultaneously and reported an aerosol that was $57 \pm 14 \%$ organic, with ammonium nitrate and ammonium sulfate the dominant inorganic species. Figure A4 shows $f(\mathrm{RH})$ for all periods when $\kappa_{\text {chem }}<0.4$ during nearly continuous operation from 5 March to 6 April 2015. These data are well fit by the $\kappa_{\text {ext }}$ parameterization and less well by the $\gamma$ parameterization (Fig. A3). This $f(\mathrm{RH})$ curve extends from 11 to $97 \% \mathrm{RH}$ and shows a sharp increase in $f(\mathrm{RH})$ above $80 \% \mathrm{RH}$ that is well captured by the $\kappa_{\text {ext }}$ functional form. 


\section{The Supplement related to this article is available online at doi:10.5194/acp-16-4987-2016-supplement.}

Author contributions. All authors contributed measurements and/or analyses for this manuscript. Charles A. Brock prepared the manuscript with substantial contributions from Nicholas L. Wagner, Timothy D. Gordon, Jose L. Jimenez, Pedro CampuzanoJost, Rebecca A. Washenfelder, Ann M. Middlebrook, and Daniel M. Murphy.

Acknowledgements. This work was supported in part by NOAA's Health of the Atmosphere and Atmospheric Chemistry, Carbon Cycle, and Climate Programs. Pedro Campuzano-Jost, Douglas A. Day, and Jose L. Jimenez were supported by NASA award NNX12AC03G/NNX15AH33A and NSF award AGS-1243354. Annmarie G. Carlton was supported by NSF award AGS-1242155. $\mathrm{Lu} \mathrm{Xu}$ and Nga L. Ng were supported by EPA award R834799 and NSF award AGS-1242258.

Disclaimer. This publication's contents do not necessarily represent the official views of the respective granting agencies. The use or mention of commercial products or services does not represent an endorsement by the authors or by any agency.

Edited by: A. Petzold

\section{References}

Attwood, A. R., Washenfelder, R. A., Brock, C. A., Hu, W., Baumann, K., Campuzano-Jost, P., Day, D. A., Edgerton, E. S., Murphy, D. M., Palm, B. B., McComiskey, A., Wagner, N. L., Sá, S. S., Ortega, A., Martin, S. T., Jimenez, J. L., and Brown, S. S.: Trends in sulfate and organic aerosol mass in the Southeast U.S.: Impact on aerosol optical depth and radiative forcing, Geophys. Res. Lett., 41, 7701-7709, doi:10.1002/2014GL061669, 2014.

Bahreini, R., Dunlea, E. J., Matthew, B. M., Simons, C., Docherty, K. S., DeCarlo, P. F., Jimenez, J. L., Brock, C. A., and Middlebrook, A. M.: Design and operation of a pressure-controlled inlet for airborne sampling with an aerodynamic aerosol lens, Aerosol Sci. Tech., 42, 465-471, doi:10.1080/02786820802178514, 2008.

Baron, P.: Aerosol Calculator Spreadsheet for Excel, available at: http://aerosols.wustl.edu/AAARworkshop08/software/ AEROCALC-11-3-03.xls (last access: 7 December 2013), 2001.

Bohren, C. F. and Huffman, D. R.: Absorption and Scattering of Light by Small Particles, John Wiley \& Sons, 1983.

Bond, T. C., Doherty, S. J., Fahey, D. W., Forster, P. M., Berntsen, T., Deangelo, B. J., Flanner, M. G., Ghan, S., Kärcher, B., Koch, D., Kinne, S., Kondo, Y., Quinn, P. K., Sarofim, M. C., Schultz, M. G., Schulz, M., Venkataraman, C., Zhang, H., Zhang, S., Bellouin, N., Guttikunda, S. K., Hopke, P. K., Jacobson, M. Z., Kaiser, J. W., Klimont, Z., Lohmann, U., Schwarz, J. P., Shindell, D., Storelvmo, T., Warren, S. G., and Zender, C. S.:
Bounding the role of black carbon in the climate system: A scientific assessment, J. Geophys. Res.-Atmos., 118, 5380-5552, doi:10.1002/jgrd.50171, 2013.

Boyd, C. M., Sanchez, J., Xu, L., Eugene, A. J., Nah, T., Tuet, W. Y., Guzman, M. I., and Ng, N. L.: Secondary organic aerosol formation from the $\beta$-pinene $+\mathrm{NO}_{3}$ system: effect of humidity and peroxy radical fate, Atmos. Chem. Phys., 15, 7497-7522, doi:10.5194/acp-15-7497-2015, 2015.

Brock, C. A., Cozic, J., Bahreini, R., Froyd, K. D., Middlebrook, A. M., McComiskey, A., Brioude, J., Cooper, O. R., Stohl, A., Aikin, K. C., de Gouw, J. A., Fahey, D. W., Ferrare, R. A., Gao, R.-S., Gore, W., Holloway, J. S., Hübler, G., Jefferson, A., Lack, D. A., Lance, S., Moore, R. H., Murphy, D. M., Nenes, A., Novelli, P. C., Nowak, J. B., Ogren, J. A., Peischl, J., Pierce, R. B., Pilewskie, P., Quinn, P. K., Ryerson, T. B., Schmidt, K. S., Schwarz, J. P., Sodemann, H., Spackman, J. R., Stark, H., Thomson, D. S., Thornberry, T., Veres, P., Watts, L. A., Warneke, C., and Wollny, A. G.: Characteristics, sources, and transport of aerosols measured in spring 2008 during the aerosol, radiation, and cloud processes affecting Arctic Climate (ARCPAC) Project, Atmos. Chem. Phys., 11, 2423-2453, doi:10.5194/acp-11-24232011, 2011.

Brock, C. A., Wagner, N. L., Anderson, B. E., Beyersdorf, A., Campuzano-Jost, P., Day, D. A., Diskin, G. S., Gordon, T. D., Jimenez, J. L., Lack, D. A., Liao, J., Markovic, M. Z., Middlebrook, A. M., Perring, A. E., Richardson, M. S., Schwarz, J. P., Welti, A., Ziemba, L. D., and Murphy, D. M.: Aerosol optical properties in the southeastern United States in summer Part 2: Sensitivity of aerosol optical depth to relative humidity and aerosol parameters, Atmos. Chem. Phys., 16, 5009-5019, doi:10.5194/acp-16-5009-2016, 2016.

Cai, Y., Montague, D., and Mooiweer-Bryan, W.: Performance characteristics of the ultra high sensitivity aerosol spectrometer for particles between 55 and $800 \mathrm{~nm}$ : Laboratory and field studies, J. Aerosol Sci., 39, 759-769, doi:10.1016/j.jaerosci.2008.04.007, 2008.

Canagaratna, M., Jayne, J., Jimenez, J., Allan, J., Alfarra, M., Zhang, Q., Onasch, T. B., Drewnick, F., Coe, H., Middlebrook, A. M., Delia, A., Williams, L. R., Trimborn, A. M., Northway, M. J., DeCarlo, P. F., Kolb, C. E., Davidovits, P., and Worsnop, D. R.: Chemical and microphysical characterization of ambient aerosols with the aerodyne aerosol mass spectrometer, Mass Spec. Rev., 26, 185-222, 2007.

Cappa, C. D., Che, D. L, Kessler, S. H., Kroll, J. H. and Wilson, K. L: Variations in organic aerosol optical and hygroscopic properties upon heterogeneous OH oxidation, J. Geophys. Res., 116, D15204, doi:10.1029/2011JD015918, 2011.

Carrico, C. M., Kreidenweis, S. M., Malm, W. C., Day, D. E., Lee, T., Carrillo, J., McMeeking, G. R., and Collett Jr., J. L.: Hygroscopic growth behavior of a carbon-dominated aerosol in Yosemite National Park, Atmos. Environ., 39, 1393-1404, doi:10.1016/j.atmosenv.2004.11.029, 2005.

Cerully, K. M., Bougiatioti, A., Hite Jr., J. R., Guo, H., Xu, L., Ng, N. L., Weber, R., and Nenes, A.: On the link between hygroscopicity, volatility, and oxidation state of ambient and water-soluble aerosols in the southeastern United States, Atmos. Chem. Phys., 15, 8679-8694, doi:10.5194/acp-15-8679-2015, 2015.

Chang, R. Y.-W., Slowik, J. G., Shantz, N. C., Vlasenko, A., Liggio, J., Sjostedt, S. J., Leaitch, W. R., and Abbatt, J. P. D.: The hy- 
groscopicity parameter $(\kappa)$ of ambient organic aerosol at a field site subject to biogenic and anthropogenic influences: relationship to degree of aerosol oxidation, Atmos. Chem. Phys., 10, 5047-5064, doi:10.5194/acp-10-5047-2010, 2010.

Charlson, R. J., Horvath, H., and Pueschel, R. F.: The direct measurement of atmospheric light scattering coefficient for studies of visibility and pollution, Atmos. Environ., 1, 469-478, 1967.

Cheung, H. H. Y., Yeung, M. C., Li, Y. J., Lee, B. P., and Chan, C. K.: Relative humidity-dependent HTDMA measurements of ambient aerosols at the HKUST supersite in Hong Kong, China, Aerosol. Sci. Tech., 49, 643-654, doi:10.1080/02786826.2015.1058482, 2015.

Chylek, P.: Extinction and liquid water content of fogs and clouds, J. Atmos. Sci., 35, 296-300, 1978.

Covert, D. S. and Charlson, R. J.: A study of the relationship of chemical composition and humidity to light scattering by aerosols, J. Appl. Meteorol., 11, 968-976, 1972.

Crumeyrolle, S., Chen, G., Ziemba, L., Beyersdorf, A., Thornhill, L., Winstead, E., Moore, R. H., Shook, M. A., Hudgins, C., and Anderson, B. E.: Factors that influence surface $\mathrm{PM}_{2.5}$ values inferred from satellite observations: perspective gained for the US Baltimore-Washington metropolitan area during DISCOVERAQ, Atmos. Chem. Phys., 14, 2139-2153, doi:10.5194/acp-142139-2014, 2014.

Day, D. A., Campuzano-Jost, P., Palm, B. B., Hu, W., Nault, B. A., Wooldridge, P. J., Cohen, R. C., Docherty, K. S., Wagner, N. L., and Jimenez, J. L.: Observations of particle organic nitrate from airborne and ground platforms in North America: Insights into vertical and geographical distributions, gas/particle partitioning, losses, and contributions to total particle nitrate, in preparation, 2016.

DeCarlo, P. F., Kimmel, J. R., Trimborn, A., Northway, M. J., Jayne, J. T., Aiken, A. C., Gonin, M., Fuhrer, K., Horvath, T., Docherty, K. S., Worsnop, D. R., and Jimenez, J. L.: Field-deployable, high-resolution, time-of-flight aerosol mass spectrometer, Anal. Chem., 78, 8281-8289, doi:10.1021/ac061249n, 2006.

Doherty, S. J., Quinn, P. K., Jefferson, A., Carrico, C. M., Anderson, T. L., and Hegg, D.: A comparison and summary of aerosol optical properties as observed in situ from aircraft, ship, and land during ACE-Asia, J. Geophys. Res., 110, D04201, doi:10.1029/2004JD004964, 2005.

Draper, D. C., Farmer, D. K., Desyaterik, Y., and Fry, J. L.: A qualitative comparison of secondary organic aerosol yields and composition from ozonolysis of monoterpenes at varying concentrations of $\mathrm{NO}_{2}$, Atmos. Chem. Phys., 15, 12267-12281, doi:10.5194/acp-15-12267-2015, 2015.

Dunlea, E. J., DeCarlo, P. F., Aiken, A. C., Kimmel, J. R., Peltier, R. E., Weber, R. J., Tomlinson, J., Collins, D. R., Shinozuka, Y., McNaughton, C. S., Howell, S. G., Clarke, A. D., Emmons, L. K., Apel, E. C., Pfister, G. G., van Donkelaar, A., Martin, R. V., Millet, D. B., Heald, C. L., and Jimenez, J. L.: Evolution of Asian aerosols during transpacific transport in INTEX-B, Atmos. Chem. Phys., 9, 7257-7287, doi:10.5194/acp-9-7257-2009, 2009.

Duplissy, J., DeCarlo, P. F., Dommen, J., Alfarra, M. R., Metzger, A., Barmpadimos, I., Prevot, A. S. H., Weingartner, E., Tritscher, T., Gysel, M., Aiken, A. C., Jimenez, J. L., Canagaratna, M. R., Worsnop, D. R., Collins, D. R., Tomlinson, J., and Baltensperger, U.: Relating hygroscopicity and composition of or- ganic aerosol particulate matter, Atmos. Chem. Phys., 11, 11551165, doi:10.5194/acp-11-1155-2011, 2011.

Dusek, U., Frank, G. P., Curtius, J., Drewnick, F., Schneider, J., Kürten, A., Rose, D., Andreae, M. O., Borrmann, S., and Pöschl, U.: Enhanced organic mass fraction and decreased hygroscopicity of cloud condensation nuclei $(\mathrm{CCN})$ during new particle formation events, Geophys. Res. Lett., 37, L03804, doi:10.1029/2009GL040930, 2010.

Esteve, A. R., Ogren, J. A., Sheridan, P. J., Andrews, E., Holben, B. N., and Utrillas, M. P.: Sources of discrepancy between aerosol optical depth obtained from AERONET and in-situ aircraft profiles, Atmos. Chem. Phys., 12, 2987-3003, doi:10.5194/acp-122987-2012, 2012.

Ferrare, R., Melfi, S., Whiteman, D., Evans, K., and Leifer, R.: Raman lidar measurements of aerosol extinction and backscattering 1. Methods and comparisons, J. Geophys. Res., 103, 1966319672, doi:10.1029/98JD01646, 1998.

Fry, J. L., Kiendler-Scharr, A., Rollins, A. W., Wooldridge, P. J., Brown, S. S., Fuchs, H., Dubé, W., Mensah, A., dal Maso, M., Tillmann, R., Dorn, H.-P., Brauers, T., and Cohen, R. C.: Organic nitrate and secondary organic aerosol yield from $\mathrm{NO}_{3}$ oxidation of $\beta$-pinene evaluated using a gas-phase kinetics/aerosol partitioning model, Atmos. Chem. Phys., 9, 14311449, doi:10.5194/acp-9-1431-2009, 2009.

Good, N., Topping, D. O., Allan, J. D., Flynn, M., Fuentes, E., Irwin, M., Williams, P. I., Coe, H., and McFiggans, G.: Consistency between parameterisations of aerosol hygroscopicity and CCN activity during the RHaMBLe discovery cruise, Atmos. Chem. Phys., 10, 3189-3203, doi:10.5194/acp-10-3189-2010, 2010a.

Good, N., Topping, D. O., Duplissy, J., Gysel, M., Meyer, N. K., Metzger, A., Turner, S. F., Baltensperger, U., Ristovski, Z., Weingartner, E., Coe, H., and McFiggans, G.: Widening the gap between measurement and modelling of secondary organic aerosol properties?, Atmos. Chem. Phys., 10, 2577-2593, doi:10.5194/acp-10-2577-2010, 2010b.

Gordon, T. D., Wagner, N. L., Richardson, M. S., Law, D. C., Wolfe, D., Eloranta, E. W., Brock, C. A., Erdesz, F., and Murphy, D. M.: Design of a novel open-path aerosol extinction cavity ringdown spectrometer, Aerosol Sci. Tech., 49, 717-726, doi:10.1080/02786826.2015.1066753, 2015.

Gunthe, S. S., King, S. M., Rose, D., Chen, Q., Roldin, P., Farmer, D. K., Jimenez, J. L., Artaxo, P., Andreae, M. O., Martin, S. T., and Pöschl, U.: Cloud condensation nuclei in pristine tropical rainforest air of Amazonia: size-resolved measurements and modeling of atmospheric aerosol composition and CCN activity, Atmos. Chem. Phys., 9, 7551-7575, doi:10.5194/acp-9-75512009, 2009.

Guo, H., Xu, L., Bougiatioti, A., Cerully, K. M., Capps, S. L., Hite Jr., J. R., Carlton, A. G., Lee, S.-H., Bergin, M. H., Ng, N. L., Nenes, A., and Weber, R. J.: Fine-particle water and $\mathrm{pH}$ in the southeastern United States, Atmos. Chem. Phys., 15, 5211-5228, doi:10.5194/acp-15-5211-2015, 2015.

Hale, G. M. and Querry, M. R.: Optical constants of water in the 200-nm to 200- $\mu \mathrm{m}$ wavelength region, Appl. Optics, 12, 555$563,1973$.

Hand, J. L. and Kreidenweis, S. M.: A new method for retrieving particle refractive index and effective density from 
aerosol size distribution data, Aerosol. Sci. Tech., 36, 10121026, doi:10.1080/02786820290092276, 2002.

Hänel, G.: Computation of the extinction of visible radiation by atmospheric aerosol particles as a function of the relative humidity, based upon measured properties, J. Aerosol Sci., 3, 377-386, doi:10.1016/0021-8502(72)90092-4, 1972a.

Hänel, G.: The ratio of the extinction coefficient to the mass of atmospheric aerosol particles as a function of the relative humidity, J. Aerosol Sci., 3, 455-460, doi:10.1016/0021-8502(72)90075-4, 1972b.

Hänel, G.: Single-scattering albedo of atmospheric aerosol particles as a function of relative humidity, J. Atmos. Sci., 33, 1120-1124, 1976.

Haynes, W. M., Lide, D. R., and Bruno, T. J.: CRC handbook of chemistry and physics: a ready-reference book of chemical and physical data, CRC Press, Boca Raton, FL, USA, 2014.

Hegg, D., Larson, T., and Yuen, P. F.: A theoretical study of the effect of relative humidity on light scattering by tropospheric aerosols, J. Geophys. Res., 98, 18435-18439, 1993.

Hersey, S. P., Craven, J. S., Metcalf, A. R., Lin, J., Lathem, T., Suski, K. J., Cahill, J. F., Duong, H. T., Sorooshian, A., Jonsson, H. H., Shiraiwa, M., Zuend, A., Nenes, A., Prather, K. A., Flagan, R. C., and Seinfeld, J. H.: Composition and hygroscopicity of the Los Angeles Aerosol: CalNex, J. Geophys. Res., 118, 30163036, doi:10.1002/jgrd.50307, 2013.

Hodas, N., Zuend, A., Mui, W., Flagan, R. C., and Seinfeld, J. H.: Influence of particle-phase state on the hygroscopic behavior of mixed organic-inorganic aerosols, Atmos. Chem. Phys., 15, 5027-5045, doi:10.5194/acp-15-5027-2015, 2015.

IPCC: Climate Change 2013: The Physical Science Basis, in: Contribution of Working Group I to the Fifth Assessment Report of the Intergovernmental Panel on Climate Change, edited by: Stocker, T. F., Qin, D., Plattner, G.-K., Tignor, M., Allen, S. K., Boschung, J., Nauels, A., Xia, Y., Bex, V., and Midgley, P. M., Cambridge University Press, Cambridge, United Kingdom and New York, NY, USA, doi:10.1017/CBO9781107415324, 2013.

Kahn, R. A.: Reducing the uncertainties in direct aerosol radiative forcing, Surv. Geophys, 33, 701-721, doi:10.1007/s10712-0119153-z, 2011.

Kasten, F.: Visibility forecast in the phase of pre-condensation, Tellus, 21, 631-635, doi:10.1111/j.2153-3490.1969.tb00469.x, 1969.

Kim, P. S., Jacob, D. J., Fisher, J. A., Travis, K., Yu, K., Zhu, L., Yantosca, R. M., Sulprizio, M. P., Jimenez, J. L., CampuzanoJost, P., Froyd, K. D., Liao, J., Hair, J. W., Fenn, M. A., Butler, C. F., Wagner, N. L., Gordon, T. D., Welti, A., Wennberg, P. O., Crounse, J. D., St. Clair, J. M., Teng, A. P., Millet, D. B., Schwarz, J. P., Markovic, M. Z., and Perring, A. E.: Sources, seasonality, and trends of southeast US aerosol: an integrated analysis of surface, aircraft, and satellite observations with the GEOS-Chem chemical transport model, Atmos. Chem. Phys., 15, 10411-10433, doi:10.5194/acp-15-10411-2015, 2015.

Koloutsou-Vakakis, S., Rood, M. J., Nenes, A., and Pilinis, C.: Modeling of aerosol properties related to direct climate forcing, J. Geophys. Res., 103, 17009-17032, 1998.

Kotchenruther, R. A., Hobbs, P. V., and Hegg, D. A.: Humidification factors for atmospheric aerosols off the mid-Atlantic coast of the United States, J. Geophys. Res., 104, 2239-2251, 1999.
Langridge, J. M., Richardson, M. S., Lack, D., Law, D., and Murphy, D. M.: Aircraft instrument for comprehensive characterization of aerosol optical properties, Part I: Wavelength-dependent optical extinction and its relative humidity dependence measured using cavity ringdown spectroscopy, Aerosol Sci. Tech., 45, 1305-1318, doi:10.1080/02786826.2011.592745, 2011.

Levin, E. J. T., Prenni, A. J., Petters, M. D., Kreidenweis, S. M., Sullivan, R. C., Atwood, S. A., Ortega, J., DeMott, P. J., and Smith, J. N.: An annual cycle of size-resolved aerosol hygroscopicity at a forested site in Colorado, J. Geophys. Res, 117, D06201, doi:10.1029/2011JD016854, 2012.

Liao, J., Froyd, K. D., Murphy, D. M., Keutsch, F. N., Yu, G., Wennberg, P. O., St. Clair, J. M., Crounse, J. D., Wisthaler, A., Mikoviny, T., Jimenez, J. L, Campuzano-Jost, P., Day, D. A., Hu, W., Ryerson, T. B., Pollack, I. B., Peischl, J., Anderson, B. E., Ziemba, L. D., Blake, D. R., Meinardi, S., and Diskin, G.: Airborne measurements of organosulfates over the continental U.S., J. Geophys. Res., 120, 2990-3005, doi:10.1002/2014JD022378, 2015.

Liu, X., Easter, R. C., Ghan, S. J., Zaveri, R., Rasch, P., Shi, X., Lamarque, J.-F., Gettelman, A., Morrison, H., Vitt, F., Conley, A., Park, S., Neale, R., Hannay, C., Ekman, A. M. L., Hess, P., Mahowald, N., Collins, W., Iacono, M. J., Bretherton, C. S., Flanner, M. G., and Mitchell, D.: Toward a minimal representation of aerosols in climate models: description and evaluation in the Community Atmosphere Model CAM5, Geosci. Model Dev., 5, 709-739, doi:10.5194/gmd-5-709-2012, 2012.

Malm, W. C., Day, D. E., and Kreidenweis, S. M.: Light scattering characteristics of aerosols as a function of relative humidity: Part I-A comparison of measured scattering and aerosol concentrations using the theoretical models, J. Air Waste Manage. As., 50, 686-700, doi:10.1080/10473289.2000.10464117, 2000.

Massoli, P., Bates, T., Quinn, P., and Lack, D.: Aerosol optical and hygroscopic properties during TexAQS-GoMACCS 2006 and their impact on aerosol direct radiative forcing, J. Geophys. Res., 114, D00F07, doi:10.1029/2008JD011604, 2009.

McNaughton, C. S., Clarke, A. D., Howell, S. G., Pinkerton, M., Anderson, B., Thornhill, L., Hudgins, C., Winstead, E., Dibb, J. E., Scheuer, E., and Maring, H.: Results from the DC-8 Inlet Characterization Experiment (DICE): Airborne versus surface sampling of mineral dust and sea salt aerosols, Aerosol Sci. Tech., 41, 136-159, doi:10.1080/02786820601118406, 2007.

Middlebrook, A. M., Bahreini, R., Jimenez, J. L., and Canagaratna, M. R.: Evaluation of composition-dependent collection efficiencies for the Aerodyne aerosol mass spectrometer using field data, Aerosol Sci. Tech., 46, 258-271, doi:10.1080/02786826.2011.620041, 2012.

Mikhailov, E., Vlasenko, S., Rose, D., and Pöschl, U.: Mass-based hygroscopicity parameter interaction model and measurement of atmospheric aerosol water uptake, Atmos. Chem. Phys., 13, 717740, doi:10.5194/acp-13-717-2013, 2013.

Murphy, D. M.: The effects of molecular weight and thermal decomposition on the sensitivity of a thermal desorption aerosol mass spectrometer, Aerosol Sci. Tech., 50, 118-125, doi:10.1080/02786826.2015.1136403, 2016.

Nemesure, S., Wagener, R., and Schwartz, S. E.: Direct shortwave forcing of climate by the anthropogenic sulfate aerosol: Sensitivity to particle size, composition, and relative humidity, J. Geophys. Res., 100, 26105-26116, 1995. 
Nguyen, T. K. V., Petters, M. D., Suda, S. R., Guo, H., Weber, R. J., and Carlton, A. G.: Trends in particle-phase liquid water during the Southern Oxidant and Aerosol Study, Atmos. Chem. Phys., 14, 10911-10930, doi:10.5194/acp-14-10911-2014, 2014.

Petters, M. D. and Kreidenweis, S. M.: A single parameter representation of hygroscopic growth and cloud condensation nucleus activity, Atmos. Chem. Phys., 7, 1961-1971, doi:10.5194/acp-71961-2007, 2007.

Petzold, A., Formenti, P., Baumgardner, D., Bundke, U., Coe, H., Curtius, J., DeMott, P. J., Flagan, R. C., Fiebig, M., Hudson, J. G., McQuaid, J., Minikin, A., Roberts, G. C., and Wang, J.: In situ measurements of aerosol particles, in: Airborne Measurements for Environmental Research: Methods and Instruments, J. Wiley \& Sons, ISBN: 978-3-527-40996-9, 157-224, 2013.

Pilat, M. J. and Charlson, R. J.: Theoretical and optical studies of humidity effects on the size distribution of a hygroscopic aerosol, Journal de Recherches Atmospheriques, 1, 165-170, 1966.

Pinnick, R. G., Jennings, S. G., and Chýlek, P.: Relationships between extinction, absorption, backscattering, and mass content of sulfuric acid aerosols, J. Geophys. Res., 85, 4059-4066, 1980.

Pringle, K. J., Tost, H., Pozzer, A., Pöschl, U., and Lelieveld, J.: Global distribution of the effective aerosol hygroscopicity parameter for $\mathrm{CCN}$ activation, Atmos. Chem. Phys., 10, 52415255, doi:10.5194/acp-10-5241-2010, 2010.

Quinn, P. K., Bates, T. S., Baynard, T., Clarke, A. D., Onasch, T. B., Wang, W., Rood, M. J., Andrews, E., Allan, J., Carrico, C. M., Coffman, D., and Worsnop, D.: Impact of particulate organic matter on the relative humidity dependence of light scattering: A simplified parameterization, Geophys. Res. Lett., 32, L22809, doi:10.1029/2005GL024322, 2005.

Rickards, A. M. J., Miles, R. E. H., Davies, J. F., Marshall, F. H., and Reid, J. P.: Measurements of the sensitivity of aerosol hygroscopicity and the $\kappa$ parameter to the $\mathrm{O} / \mathrm{C}$ ratio, J. Phys. Chem. A, 117, 14120-14131, doi:10.1021/jp407991n, 2013.

Rissler, J., Vestin, A., Swietlicki, E., Fisch, G., Zhou, J., Artaxo, P., and Andreae, M. O.: Size distribution and hygroscopic properties of aerosol particles from dry-season biomass burning in Amazonia, Atmos. Chem. Phys., 6, 471-491, doi:10.5194/acp6-471-2006, 2006.

Santarpia, J. L., Gasparini, R., Li, R., and Collins, D. R.: Diurnal variations in the hygroscopic growth cycles of ambient aerosol populations, J. Geophys. Res., 110, D03206, doi:10.1029/2004JD005279, 2005.

Schwarz, J. P., Perring, A. E., Markovic, M. Z., Gao, R. S., Ohata, S., Langridge, J., Law, D., McLaughlin, R., and Fahey, D. W.:, Technique and theoretical approach for quantifying the hygroscopicity of black-carbon-containing aerosol using a single particle soot photometer J. Aerosol Sci., 81, 110-126, doi:10.1016/j.jaerosci.2014.11.009, 2015.

Sihto, S.-L., Mikkilä, J., Vanhanen, J., Ehn, M., Liao, L., Lehtipalo, K., Aalto, P. P., Duplissy, J., Petäjä, T., Kerminen, V.-M., Boy, M., and Kulmala, M.: Seasonal variation of CCN concentrations and aerosol activation properties in boreal forest, Atmos. Chem. Phys., 11, 13269-13285, doi:10.5194/acp-11-13269-2011, 2011.

Stokes, R. H. and Robinson, R. A.: Interactions in aqueous nonelectrolyte solutions. I. Solute-solvent equilibria, J. Phys. Chem., 70, 2126-2131, doi:10.1021/j100879a010, 1966.

Suda, S. R., Petters, M. D., Matsunaga, A., Sullivan, R. C., Ziemann, P. J., and Kreidenweis, S. M.: Hygroscopicity frequency distributions of secondary organic aerosols, J. Geophys. Res., 117, D04207, doi:10.1029/2011JD016823, 2012.

Tang, I. N.: Chemical and size effects of hygroscopic aerosols on light scattering coefficients, J. Geophys. Res., 101, 1924519250, 1996.

Toon, O. B., Pollack, J. B., and Khare, B. N., The optical constants of several atmospheric aerosol species: Ammonium sulfate, aluminum oxide, and sodium chloride, J. Geophys. Res., 81, 57335748, doi:10.1029/JC081i033p05733, 1976.

van Donkelaar, A., Martin, R. V., Brauer, M., and Boys, B. L.: Use of satellite observations for long-term exposure assessment of global concentrations of fine particulate matter, Environ. Health Persp., 123, 135-143, doi:10.1289/ehp.1408646, 2015.

Varma, R. M., Ball, S. M., Brauers, T., Dorn, H.-P., Heitmann, U., Jones, R. L., Platt, U., Pöhler, D., Ruth, A. A., Shillings, A. J. L., Thieser, J., Wahner, A., and Venables, D. S.: Light extinction by secondary organic aerosol: an intercomparison of three broadband cavity spectrometers, Atmos. Meas. Tech., 6, 3115-3130, doi:10.5194/amt-6-3115-2013, 2013.

Voss, K., Welton, E., Quinn, P., Frouin, R., Miller, M., and Reynolds, R.: Aerosol optical depth measurements during the Aerosols99 experiment, J. Geophys. Res., 106, 20821-20831, doi:10.1029/2000JD900783, 2001.

Wagner, N. L., Brock, C. A., Angevine, W. M., Beyersdorf, A., Campuzano-Jost, P., Day, D., de Gouw, J. A., Diskin, G. S., Gordon, T. D., Graus, M. G., Holloway, J. S., Huey, G., Jimenez, J. L., Lack, D. A., Liao, J., Liu, X., Markovic, M. Z., Middlebrook, A. M., Mikoviny, T., Peischl, J., Perring, A. E., Richardson, M. S., Ryerson, T. B., Schwarz, J. P., Warneke, C., Welti, A., Wisthaler, A., Ziemba, L. D., and Murphy, D. M.: In situ vertical profiles of aerosol extinction, mass, and composition over the southeast United States during SENEX and SEAC ${ }^{4}$ SS: observations of a modest aerosol enhancement aloft, Atmos. Chem. Phys., 15, 7085-7102, doi:10.5194/acp-15-7085-2015, 2015

Warren, S. G., Hahn, C. J., London, J., Chervin, R. M., and Jenne, R. L.: Global Distribution of Total Cloud Cover and Cloud Type Amounts over Land., NCAR Tech. Note TN-273_STR, 1232, available at: http://www.atmos.washington.edu/CloudMap/ Publications/index.html (last access: 6 June 2015), 1986.

Washenfelder, R. A., Attwood, A. R., Brock, C. A., Guo, H., Xu, L., Weber, R. J., Ng, N. L., Allen, H. M., Ayres, B. R., Baumann, K., Cohen, R. C., Draper, D. C., Duffey, K. C., Edgerton, E., Fry, J. L., Hu, W. W., Jimenez, J. L., Palm, B. B., Romer, P., Stone, E. A., Wooldridge, P. J., and Brown, S. S.: Biomass burning dominates brown carbon absorption in the rural southeastern United States, Geophys. Res. Lett., 42, 653-664, doi:10.1002/2014GL062444, 2015.

Wex, H., Petters, M. D., Carrico, C. M., Hallbauer, E., Massling, A., McMeeking, G. R., Poulain, L., Wu, Z., Kreidenweis, S. M., and Stratmann, F.: Towards closing the gap between hygroscopic growth and activation for secondary organic aerosol: Part $1-\mathrm{Ev}-$ idence from measurements, Atmos. Chem. Phys., 9, 3987-3997, doi:10.5194/acp-9-3987-2009, 2009.

Wright, H. L.: Atmospheric opacity: a study of visibility observations in the British Isles, Q. J. Roy. Meteor. Soc., 65, 411-442, 1939.

Xu, L., Guo, H., Boyd, C. M., Klein, M., Bougiatioti, A., Cerully, K. M., Hite, J. R., Isaacman-VanWertz, G., Kreisberg, N. M., Knote, C., Olson, K., Koss, A., Goldstein, A. H., Hering, S. V., de Gouw, 
J., Baumann, K., Lee, S.-H., Nenes, A., Weber, R. J., and Ng, N. L.: Effects of anthropogenic emissions on aerosol formation from isoprene and monoterpenes in the southeastern United States, P. Natl. Acad. Sci., 112, 37-42, 2015a.

Xu, L., Suresh, S., Guo, H., Weber, R. J., and Ng, N. L.: Aerosol characterization over the southeastern United States using highresolution aerosol mass spectrometry: spatial and seasonal variation of aerosol composition and sources with a focus on organic nitrates, Atmos. Chem. Phys., 15, 7307-7336, doi:10.5194/acp15-7307-2015, 2015b.

Zaveri, R. A.: A new method for multicomponent activity coefficients of electrolytes in aqueous atmospheric aerosols, J. Geophys. Res., 110, D02201, doi:10.1029/2004JD004681, 2005.

Zhang, Q., Jimenez, J. L., Canagaratna, M. R., Allan, J. D., Coe, H., Ulbrich, I., Alfarra, M. R., Takami, A., Middlebrook, A. M., Sun, Y. L., Dzepina, K., Dunlea, E., Docherty, K., DeCarlo, P. F., Salcedo, D., Onasch, T., Jayne, J. T., Miyoshi, T., Shimono, A., Hatakeyama, S., Takegawa, N., Kondo, Y., Schneider, J., Drewnick, F., Borrmann, S., Weimer, S., Demerjian, K., Williams, P., Bower, K., Bahreini, R., Cottrell, L., Griffin, R. J., Rautiainen, J., Sun, J. Y., Zhang, Y. M., and Worsnop, D. R.: Ubiquity and dominance of oxygenated species in organic aerosols in anthropogenically-influenced Northern Hemisphere midlatitudes, Geophys. Res. Lett., 34, L13801, doi:10.1029/2007GL029979, 2007.

Zieger, P., Fierz-Schmidhauser, R., Gysel, M., Ström, J., Henne, S., Yttri, K. E., Baltensperger, U., and Weingartner, E.: Effects of relative humidity on aerosol light scattering in the Arctic, Atmos. Chem. Phys., 10, 3875-3890, doi:10.5194/acp-10-38752010, 2010.

Zieger, P., Weingartner, E., Henzing, J., Moerman, M., de Leeuw, G., Mikkilä, J., Ehn, M., Petäjä, T., Clémer, K., van Roozendael, M., Yilmaz, S., Frieß, U., Irie, H., Wagner, T., Shaiganfar, R., Beirle, S., Apituley, A., Wilson, K., and Baltensperger, U.: Comparison of ambient aerosol extinction coefficients obtained from in-situ, MAX-DOAS and LIDAR measurements at Cabauw, Atmos. Chem. Phys., 11, 2603-2624, doi:10.5194/acp11-2603-2011, 2011.
Zieger, P., Kienast-Sjögren, E., Starace, M., von Bismarck, J., Bukowiecki, N., Baltensperger, U., Wienhold, F. G., Peter, T., Ruhtz, T., Collaud Coen, M., Vuilleumier, L., Maier, O., Emili, E., Popp, C., and Weingartner, E.: Spatial variation of aerosol optical properties around the high-alpine site Jungfraujoch (3580 m a.s.1.), Atmos. Chem. Phys., 12, 72317249, doi:10.5194/acp-12-7231-2012, 2012.

Zieger, P., Fierz-Schmidhauser, R., Weingartner, E., and Baltensperger, U.: Effects of relative humidity on aerosol light scattering: results from different European sites, Atmos. Chem. Phys., 13, 10609-10631, doi:10.5194/acp-13-10609-2013, 2013.

Zieger, P., Fierz-Schmidhauser, R., Poulain, L., Müller, T., Birmili, W., Spindler, G.,Wiedensohler, A., Baltensperger, U., and Weingartner, E.: Influence of water uptake on the aerosol particle lightscattering coeffcients of the Central European aerosol, Tellus B, 66, 22716, doi:10.3402/tellusb.v66.22716, 2014.

Zieger, P., Aalto, P. P., Aaltonen, V., Äijälä, M., Backman, J., Hong, J., Komppula, M., Krejci, R., Laborde, M., Lampilahti, J., de Leeuw, G., Pfüller, A., Rosati, B., Tesche, M., Tunved, P., Väänänen, R., and Petäjä, T.: Low hygroscopic scattering enhancement of boreal aerosol and the implications for a columnar optical closure study, Atmos. Chem. Phys., 15, 7247-7267, doi:10.5194/acp-15-7247-2015, 2015.

Ziemba, L. D., Hudgins, C. H., Obland, M. D., Rogers, R. R., Scarino, A. J., Winstead, E. L., Anderson, B. E., Thornhill, K. L., Ferrare, R., Barrick, J., Beyersdorf, A. J., Chen, G., Crumeyrolle, S., Hair, J., and Hostetler, C. A.: Airborne observations of aerosol extinction by in-situ and remote-sensing techniques: Evaluation of particle hygroscopicity, Geophys. Res. Lett., 40, 417-422, doi:10.1029/2012GL054428, 2012. 